\title{
MANEJO DE CULTIVARES DE ALGODOEIRO EM DENSIDADE POPULACIONAL VARIÁVEL COM O USO DE REGULADOR DE CRESCIMENTO
}

\author{
GRACIELA DECIAN ZANON
}

Dissertação apresentada à Escola Superior de Agricultura "Luiz de Queiroz", Universidade de São Paulo, para obtenção do título de Mestre em Agronomia, Área de Concentração: Fitotecnia.

PIRACICABA

Estado de São Paulo - Brasil

Outubro -2002 


\section{MANEJO DE CULTIVARES DE ALGODOEIRO EM DENSIDADE POPULACIONAL VARIÁVEL COM O USO DE REGULADOR DE CRESCIMENTO}

\section{GRACIELA DECIAN ZANON}

Engenheira Agrônoma

Orientador: Prof. Dr. EDERALDO JOSÉ CHIAVEGATO

Dissertação apresentada à Escola Superior de Agricultura "Luiz de Queiroz", Universidade de São Paulo, para obtenção do título de Mestre em Agronomia, Área de Concentração: Fitotecnia.

PIRACICABA

Estado de São Paulo - Brasil

Outubro -2002 


\section{Dados Internacionais de Catalogação na Publicação (CIP) DIVISÃO DE BIBLIOTECA E DOCUMENTAÇÃO - ESALQ/USP}

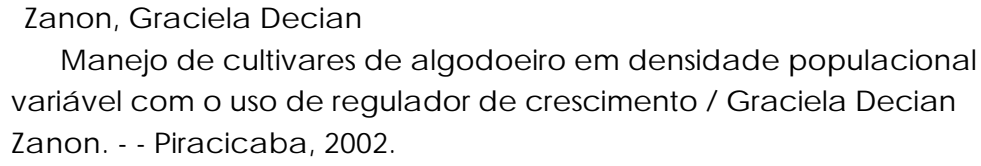

$75 \mathrm{p}$.

Dissertação (mestrado) - - Escola Superior de Agricultura Luiz de Queiroz, 2002.

Bibliografia.

1. Algodão 2. Densidade popula cional 3. Espaça mento 4. Reguladores de cresc imento vegetal 5. Variedades I. Título

CDD 633.51

\section{"Permitida a cópia total ou parcial deste documento, desde que citada a fonte - $\mathrm{O}$ autor"}


À minha mãe, por me dar a vida e me ajudar a viver.

Ao теи pai, por sempre acreditar em mim.

Ao теи irmão, pela força.

Ao meи esposo, pelo companheirismo.

OFEREÇO

A minha filha Carolina, parte desta realização... DEDICO 


\section{AGRADECIMENTOS}

Meu reconhecimento ao Prof. Dr. Ederaldo José Chiavegato da USP/ESALQ, pela orientação, dedicação e paciência.

À "Escola Superior de Agricultura Luiz de Queiroz", Universidade de São Paulo, pela oportunidade. À FAPESP - Fundação de Amparo à Pesquisa do Estado de São Paulo pelo apoio financeiro. Ao Centro de Análise e Pesquisa Tecnológica do Agronegócio de Grãos e Fibras do IAC - Instituto Agronômico de Campinas/APTA, pela contribuição prestada para a realização desta pesquisa.

As amigas Estatísticas Glaucy da Conceição Ortiz e Andréia da Silva Meyer, que tanto me ajudaram de forma profissional e pessoal durante a realização deste projeto. À Cláudia dos Santos Gay , Ana Sanches e sua família pelo carinho e atenção.

Aos colegas do GEALG - Grupo de Experimentação na Cultura do Algodão da USP/ESALQ, pela colaboração nos trabalhos de campo.

Aos professores, colegas e funcionários que ajudaram nesta caminhada. Aqueles que em qualquer momento se colocaram disponíveis, sem citar nomes, para não correr o risco de esquecer de alguém, pois tantos foram aqueles que colaboraram para esta realização. A todos a minha gratidão.

E a Deus, por tornar tudo possível. 


\section{SUMÁRIO}

\begin{tabular}{|c|c|}
\hline & Página \\
\hline LISTA DE TABELAS.. & vii \\
\hline LISTA DE FIGURAS.. & $\mathrm{xi}$ \\
\hline RESUMO...... & xii \\
\hline SUMMARY.. & xiv \\
\hline 1 INTRODUÇÃO........ & 1 \\
\hline 2 REVISÃO DE LITERATURA..... & 3 \\
\hline 2.1 A cultura............................ & 3 \\
\hline 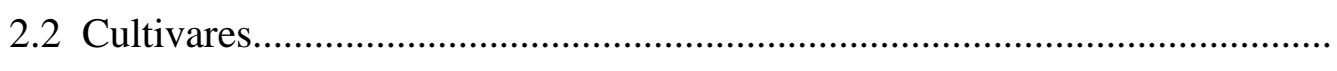 & 5 \\
\hline 2.3 Espaçamento.......... & 6 \\
\hline 2.4 Regulador de crescimento..... & 11 \\
\hline 3 MATERIAL E MÉTODOS.................. & 15 \\
\hline 3.1 Local e período da experimentação.... & 15 \\
\hline 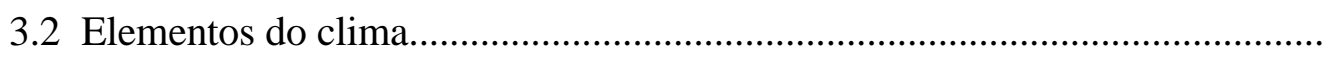 & 15 \\
\hline 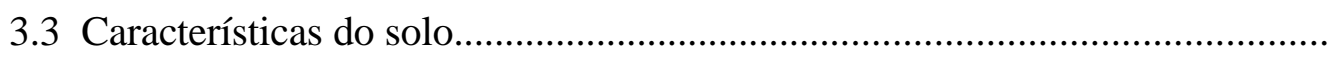 & 16 \\
\hline 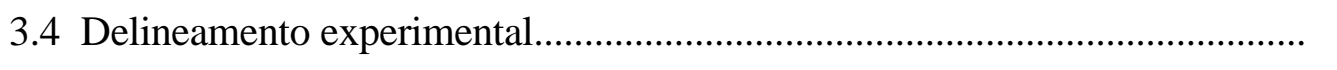 & 17 \\
\hline 3.5 Condução do experimento................ & 18 \\
\hline 3.6 Acompanhamento fenológico........... & 20 \\
\hline 3.7 Variáveis analisadas................................. & 20 \\
\hline 3.7.1 Produção e precocidade de colheita................... & 20 \\
\hline 3.7.2 Caracteres agronômicos de campo.. & 21 \\
\hline
\end{tabular}


3.7.3 Caracteres agronômicos de laboratório....................................................... 22

3.7.4 Características tecnológicas da fibra.......................................................... 22

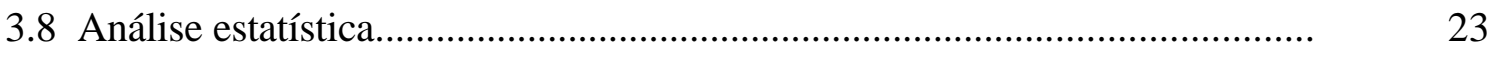

4 RESULTADOS E DISCUSSÃO............................................................ 24

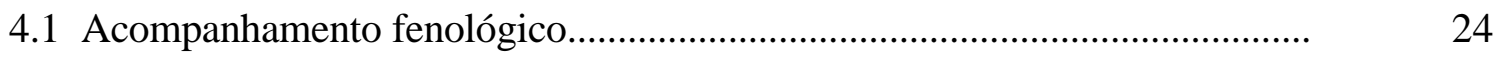

4.2 Produção de algodão em caroço e precocidade de colheita.................................. 26

4.2.1 Produção de algodão em caroço.................................................................. 26

4.2.2 Precocidade de colheita..................................................................... 29

4.3 Caracteres agronômicos de campo.......................................................... 31

4.3.1 Altura de plantas................................................................................ 31

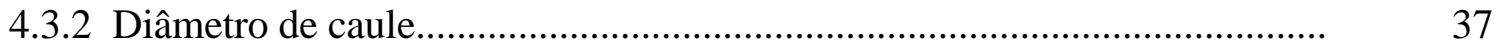

4.3.3 Número médio de capulhos por plantas.................................................... 41

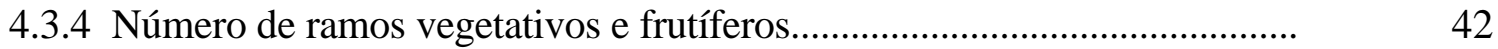

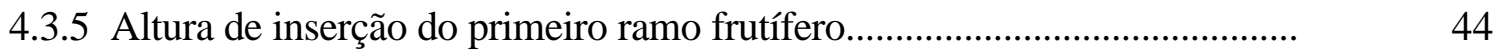

4.3.6 Conformação de planta...................................................................... 44

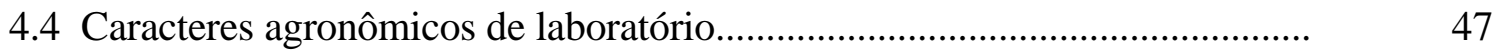

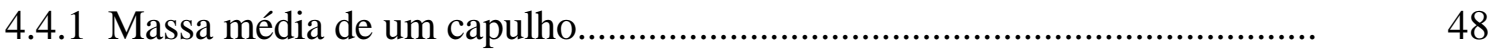

4.4.2 Porcentagem de fibras.......................................................................... 49

4.4.3 Massa de 100 sementes........................................................................... 52

4.5 Características tecnológicas da fibra......................................................... 53

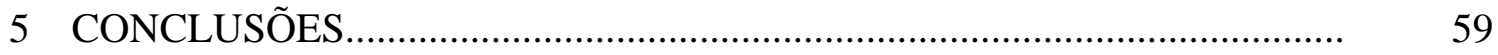

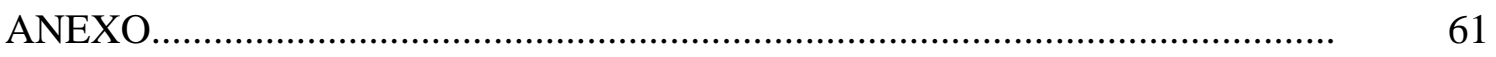

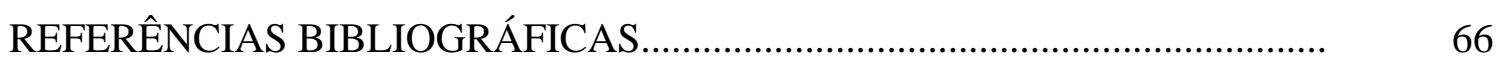




\section{LISTA DE TABELAS}

Página

1 Resultados da análise química do solo da área experimental, na

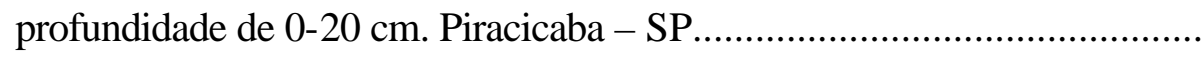

2 Resultados da análise química do solo da área experimental, na profundidade de $0-20 \mathrm{~cm}$. Piracicaba - SP...............................................

3 Esquema da análise de variância para os dados das variáveis estudadas.

4 Número médio de dias e unidades de calor (UC) para as cultivares IAC 23, DeltaOpal e CD 01 obtidos durante as fases de crescimento da cultura. Ano agrí́cola 2000/01. Piracicaba, SP

5 Quadrado médio (QM), F da análise de variância (F) e coeficiente de variação dos resíduos $(\mathrm{CV})$ referentes à produção e precocidade para espaçamentos (E), cultivares (V), regulador de crescimento (R) e suas interações (média de 4 repetições). Piracicaba, SP

6 Produção e Precocidade de colheita . Piracicaba, SP.

7 Produção: Interação cultivar $\mathrm{x}$ espaçamento e cultivar $\mathrm{x}$ regulador de crescimento. Piracicaba, SP. 
8 Precocidade de colheita: Interação cultivar $\mathrm{x}$ espaçamento. Piracicaba, SP.

9 Quadrado médio (QM), F da análise de variância $(\mathrm{F})$ e coeficiente de variação dos resíduos $(\mathrm{CV})$ referentes à altura de plantas para espaçamentos (E), cultivares (V), regulador de crescimento $(R)$ e suas interações (média de 4 repetições). Piracicaba, SP

10 Caracteres agronômicos de campo: altura de plantas (cm). Piracicaba, SP.

11 Caracteres agronômicos de campo: Interação cultivar $\mathrm{x}$ espaçamento para a altura de plantas $(\mathrm{cm})$. Piracicaba, SP.

12 Caracteres agronômicos de campo: Interação cultivar $\mathrm{x}$ regulador de crescimento para a altura de plantas $(\mathrm{cm})$. Piracicaba, SP.

13 Caracteres agronômicos de campo: Interação espaçamento $\mathrm{x}$ cultivar $\mathrm{x}$ regulador de crescimento para a altura de plantas $(\mathrm{cm})$. Piracicaba, SP.

14 Quadrado médio (QM), F da análise de variância (F) e coeficiente de variação dos resíduos (CV) referentes aos parâmetros avaliados das características de campo para espaçamentos (E), cultivares (V), regulador de crescimento $(\mathrm{R})$ e suas interações (média de 4 repetições). Piracicaba, SP.

15 Caracteres agronômicos de campo: diâmetro de caule, número de maçãs por planta, número de ramos vegetativos e frutíferos e altura de inserção do primeiro ramo frutífero. Piracicaba, SP.

16 Caracteres agronômicos de campo: Interação espaçamento $\mathrm{x}$ cultivar $\mathrm{x}$ regulador de crescimento para o diâmetro do caule (mm). Piracicaba, SP. 
17 Caracteres agronômicos de campo: Interação cultivar $\mathrm{x}$ regulador de crescimento para o número de ramos frutíferos. Piracicaba, SP.

18 Quadrado médio (QM), F da análise de variância (F) e coeficiente de variação dos resíduos (CV) referentes aos parâmetros avaliados das características de campo para espaçamentos (E), cultivares (V), regulador de crescimento $(\mathrm{R})$ e suas interações (média de 4 repetições). Piracicaba, SP

19 Caracteres agronômicos de campo: Interação cultivar $\mathrm{x}$ regulador de crescimento para o número de ramos frutíferos e comprimento do primeiro ramo frutífero. Piracicaba, SP.

20 Caracteres agronômicos de campo: comprimento do primeiro ramo frutífero (RF), comprimento do ramo frutífero mediano Piracicaba, SP.

21 Quadrado médio (QM), F da análise de variância (F) e coeficiente de variação dos resíduos (CV) referentes aos parâmetros avaliados das características agronômicos de laboratório para espaçamentos (E), cultivares $(\mathrm{V})$, regulador de crescimento $(\mathrm{R})$ e suas interações (média de 4 repetições). Piracicaba, SP.

22 Caracteres agronômicos de laboratório: Massa média de um capulho, porcentagem de fibra e massa de 100 sementes. Piracicaba, SP.

23 Quadrado médio (QM), F da análise de variância $(\mathrm{F})$ e coeficiente de variação dos resíduos (CV) referentes aos parâmetros avaliados das características tecnológicas da fibra para espaçamentos $(\mathrm{E})$, cultivares (V), regulador de crescimento (R) e suas interações (média de 4 repetições). Piracicaba, SP. 
24 Comprimento da fibra (mm), uniformidade (\%), maturidade (\%), tenacidade (g/Tex) e micronaire $(\mathrm{mm})$ referentes aos parâmetros avaliados das características tecnológicas da fibra para espaçamentos (E), cultivares (V), regulador de crescimento (R) e suas interações (média de 4 repetições). Piracicaba, SP

25 Características tecnológicas da fibra - Interação cultivar x regulador de crescimento para tenacidade (g/Tex). Piracicaba, SP............................

26 Características tecnológicas da fibra: tenacidade (gf/Tex) - Interação espaçamento $\mathrm{x}$ cultivar $\mathrm{x}$ regulador de crescimento. Piracicaba, SP 


\section{LISTA DE FIGURAS}

Página

1. Distribuição acumulada de chuvas, em cada decênio, durante o período de outubro de 2000 a maio de 2001.Piracicaba , SP.............................................. 62

2. Distribuição de chuvas durante o período de outubro de 2000 a maio de 2001 e médias de precipitações acumuladas nos últimos cinco anos.

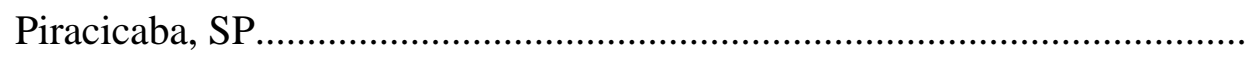

3. Temperaturas máxima, mínima e média, ocorridas no período de outubro de 2000 a maio de 2001. Piracicaba, SP.

4. Temperaturas médias ocorridas no período de outubro de 2000 a maio de 2001 e média das temperaturas dos últimos cinco anos. Piracicaba, SP

5. Radiação Global (cal/cm/d) no período de outubro de 2000 a abril de 2001. Piracicaba, SP

6. Insolação (h/d) no período de outubro de 2000 a abril de 2001. Piracicaba, SP

7. Unidade relativa do ar e média mensal no período de outubro de 2000 a abril de 2001. Piracicaba, SP. 


\title{
MANEJO DE CULTIVARES DE ALGODOEIRO EM DENSIDADE POPULACIONAL VARIÁVEL COM O USO DE REGULADOR DE CRESCIMENTO
}

\author{
Autora: GRACIELA DECIAN ZANON \\ Orientador: Prof. Dr. EDERALDO JOSÉ CHIAVEGATO
}

\section{RESUMO}

Com o objetivo de estudar o comportamento fenológico, morfológico e produtivo de cultivares de algodoeiro com diferentes arquiteturas de plantas em diferentes espaçamentos, através do manejo com regulador de crescimento, foi realizado o presente trabalho, na área experimental da ESALQ/USP, no município de Piracicaba, Estado de São Paulo, no ano agrícola de 2000/01. O delineamento experimental utilizado foi o de blocos ao acaso com parcelas sub-subdivididas e 4 repetições. As parcelas constituíram-se dos espaçamentos de 0,76 e 1,01 m, as subparcelas das três cultivares (IAC 23, DeltaOpal e CD 401) e as sub-subparcelas em presença ou ausência de regulador de crescimento. Em seis plantas marcadas de cada parcela foram analisados os seguintes parâmetros: acompanhamento das fases fenológicas (emergência, aparecimento do primeiro botão floral, antese da primeira flor e abertura do primeiro capulho) e caracteres agronômicos de campo (altura de planta, diâmetro do caule, número de ramos vegetativos e frutíferos, conformação da planta, número de capulhos por planta e altura de inserção do primeiro ramo frutífero). $\mathrm{Na}$ área útil de cada parcela foi determinada, a produção de algodão em caroço por hectare e a precocidade de colheita. Em amostras de 20 capulhos tomadas aleatoriamente em cada parcela foram 
realizadas as análises dos caracteres agronômicos de laboratório (massa de 100 sementes, porcentagem de fibras e massa média de um capulho) e das características tecnológicas da fibra (comprimento, uniformidade de comprimento, maturidade, tenacidade e índice micronaire). Os resultados obtidos permitem concluir que não houve interações significativas para as cultivares $\mathrm{x}$ espaçamentos $\mathrm{x}$ regulador de crescimento, para a produção de algodão em caroço, precocidade de colheita, caracteres agronômicos de laboratório e características tecnológicas das fibras, com exceção da tenacidade. Desta forma, as cultivares avaliadas, independente da arquitetura da planta, apresentaram capacidade de ajustar-se às variações dos espaçamentos testados e aplicação de regulador de crescimento com relação a estas características. Os caracteres agronômicos de campo como: a altura das plantas e o diâmetro de caule, de modo geral, apresentaram médias reduzidas com a redução do espaçamento e aplicação do regulador de crescimento, para as cultivares de desenvolvimento mais vigoroso (IAC 23 e DeltaOpal), não influenciando, porém, a cultivar de plantas morfologicamente mais compactas (CD 401). 


\title{
MANAGEMENT OF COTTON CULTIVARS UNDER VARIABLE PLANT DENSITIES USING A PLANT GROWTH REGULATOR
}

\author{
Author: GRACIELA DECIAN ZANON \\ Adviser: Prof. Dr. EDERALDO JOSÉ CHIAVEGATO
}

\section{SUMMARY}

The purpose of this work was to study the phenological, morphological and productive behavior of cotton cultivars presenting different plant shapes under different spacing layouts managed with the use of plant growth regulator. The experiment was established in the experimental field of ESALQ/USP, Piracicaba, Sao Paulo, during the 2000/01 growing season and was arranged in a randomized block experimental design with subdivided plots and 4 replications. The plots represented spacing layouts of 0.76 and $1.01 \mathrm{~m}$, subplots consisted of the IAC 23, DeltaOpal and CD 401 cultivars, while the sub-subplots were characterized by the use or absence of growth regulator. Six plants per plot were labeled and analyzed for the phenological phases (emergence, appearance of the first flower bud, anthesis of the first flower, opening of the first cotton boll) and field agronomical characteristics (plant height, stem diameter, number of vegetative and fruit branches, plant shape, number of cotton boll per plant and insertion height of the first fruit branch). The harvest early and raw cotton yield per hectare were determined considering the effective plot area. The agronomical lab characteristics (mass of 100 seeds, fiber percentage and cotton boll mass), as well as the 
fiber technological characteristics (length, length uniformity, maturity, strength, and micronaire) were analyzed using a sample of 20 bolls taken at random. Based on the results obtained, it can be concluded that there were no significant interactions among cultivars $\mathrm{x}$ spacing $\mathrm{x}$ growth regulator, as to cotton yield, harvest early, agronomical lab characteristics and fiber technological characteristics, except for stremgth. The analyzed cultivars, regardless of the plant shape, showed good adaptation to the variation in spacing layouts, as well as to the application of growth regulator, considering the analyzed characteristics. The field agronomical characteristics, such as plant height and stem diameter, generally decreased with the reduction in spacing and with the application of growth regulator, considering the most vigorous cultivars (IAC 23 and DeltaOpal). On the other hand, the cultivar presenting a more compact plant (CD 401) pattern was not influenced by spacing or use of growth regulator. 


\section{INTRODUÇÃO}

A pluma do algodoeiro é considerada a mais importante dentre as fibras têxteis naturais e artificiais. A cultura do algodoeiro herbáceo apresenta relevante importância econômica e social m Brasil e no mundo e está situada entre as dez maiores fontes de riqueza no setor agropecuário brasileiro.

Segundo dados do FNP - Consultoria \& Comércio (2002), a cultura do algodoeiro está presente em dezessete estados brasileiros sob as mais variadas condições de ambiente e ocupa cerca de 887 mil hectares. Dessa área, tem-se uma produção anual de 2.648 mil toneladas de algodão em caroço ou cerca de 916 mil toneladas de pluma. Em termos gerais, o Brasil deu um salto na produtividade de algodão quando se compara a safra 97/98 com a safra 00/01, saindo de uma produtividade média de 1444 kg.ha ${ }^{-1}$ para $2983 \mathrm{~kg} . \mathrm{ha}^{-1}$, o que representa um aumento de $106 \%$.

A cotonicultura brasileira, nos moldes como estava sendo conduzida nas últimas décadas, passou por mudanças fundamentais. A produção de algodão deixou de ser uma atividade de pequenas propriedades para se tornar uma cultura de grandes propriedades altamente tecnificadas. Os aumentos consideráveis na produtividade são consequiência da ação conjunta da expansão da área de cultivo para diferentes regiões edafoclimáticas e do elevado nível tecnológico da cultura.

$\mathrm{O}$ atual sistema de cultivo utilizado para o algodoeiro prioriza a produção e a qualidade de fibra, onde a mecanização se faz presente da semeadura à colheita, associado à utilização intensiva de insumos agrícolas. Apesar da alta rentabilidade obtida, o custo médio da lavoura aumentou significativamente nas últimas safras. Para que este cenário se modifique é necessário que o sistema produtivo seja sustentado, sobretudo pelo uso de cultivares potencialmente produtivas ou seja, altamente 
responsivas aos insumos utilizados, resistentes às principais pragas e doenças e manejadas adequadamente durante todo o ciclo da cultura.

Para o sucesso de qualquer exploração agrícola e em especial na cotonicultura herbácea, duas rotas devem ser consideradas continuamente: a genética, onde se busca a melhoria da qualidade da fibra, incremento na porcentagem da fibra, aumento na produtividade e resistência ampla a pragas e em especial a doenças, visando reduzir custos de produção e os níveis de agressão ao meio ambiente e; a rota denominada ambiental, onde manipulam-se insumos e alguns fatores de produção, além de aspectos da cultura, como o espaçamento, a densidade de semeadura, a época ideal de semeadura, os métodos de preparo do solo entre outros, objetivando a produtividade máxima econômica, com sustentabilidade global (Beltão et al., 1999).

Na genética, o processo de obtenção de cultivares é dinâmico e contínuo: periodicamente a pesquisa recomenda novas cultivares em substituição àquelas que estão sendo utilizadas pelos cotonicultores. Cada cultivar lançada no mercado possui suas particularidades de manejo, e é neste ponto que as rotas acima mencionadas se encontram.

Admitindo-se que apenas o potencial genético não assegura o êxito da cultura, dependendo-se para isso da ação combinada de fatores genéticos e de fatores controláveis e incontroláveis do ambiente (interação genótipo x ambiente) (Fuzatto, 1987), uma cultivar apenas irá expressar todo o seu potencial produtivo se for manejada adequadamente.

O presente trabalho teve por objetivo estudar o comportamento fenológico, morfológico e produtivo de cultivares de algodoeiro com características distintas de arquitetura de plantas em diferentes espaçamentos, através do manejo com regulador de crescimento visando à adequação de cultivares para atender a racionalização de diferentes operações técnicas de cultivo, bem como, a identificação de cultivares com potencial de utilização para diferentes sistemas de produção, através de técnicas de manejo, diante de fatores do ambiente e técnicas de cultivo. 


\section{REVISÃO DE LITERATURA}

\subsection{A Cultura}

De acordo com Beltrão et al. (1999), o algodoeiro herbáceo (Gossypium hirsutum L. var. latifolium Hutch.) é uma planta de origem tropical e subtropical necessitando, para externar elevadas produtividades e fibra de alta qualidade, de dias ensolarados, com menos de $30 \%$ de nebulosidade, temperatura média do ar acima de $20^{\circ} \mathrm{C}$, umidade relativa do ar média em torno de $60 \%$, e inexistência de inversão térmica e de precipitação pluvial entre 500 a $1800 \mathrm{~mm}$, sendo que as precipitações devem ser bem distribuídas, devendo ser maiores nos períodos de floração, crescimento e desenvolvimento dos frutos e; insolação total e escassez hídrica na colheita, pois a energia solar é um dos componentes principais para a abertura dos frutos.

O algodoeiro herbáceo é um dos fitossistemas de maior complexidade que se encontra na natureza (Oosterhuis, 1999). Durante a maior parte do ciclo da planta, há diversos eventos ocorrendo ao mesmo tempo, como crescimento vegetativo, aparecimento de gemas reprodutivas, florescimento, crescimento e maturação dos frutos. Cada um destes eventos é importante para a produção final, mas é necessário que eles ocorram de modo balanceado. Durante boa parte do ciclo da planta, ocorre uma forte competição interna pelos carboidratos da fotossíntese. Entender os principais processos fisiológicos que ocorrem durante cada estágio de crescimento é importante para o manejo adequado da cultura para obtenção de produções econômicas (Rosolem, 2001). 
Como a planta do algodoeiro tem seu crescimento e desenvolvimento fortemente influenciados pela temperatura, a determinação da exigência térmica para cada fase de crescimento é uma forma de esclarecer e predizer a ocorrência dos eventos e sua duração durante as fases de crescimento e desenvolvimento. Esta determinação, referindo-se a unidades de calor (UC), é obtida pelas medidas das temperaturas máximas e mínimas diárias e subtraída a temperatura base. Nos Estados Unidos a exigência de unidades de calor, das cultivares utilizadas, da semeadura a colheita é de aproximadamente 2.600 (Oosterhuis, 1999). No Brasil, segundo Rosolem (2001), a exigência de unidades de calor para as cultivares ITA 90 e Antares, no Mato Grosso, da emergência ao primeiro capulho é de 1287, e provavelmente, necessitará de menos unidades de calor até a colheita que as cultivares nos Estados Unidos.

Não ocorrendo condições adversas de estresse de umidade, temperatura, pragas e doenças, o ciclo do algodoeiro pode ser dividido em cinco fases. A primeira compreende a semeadura à emergência. Fase em que ocorre a embebição, germinação da semente e estabelecimento dos cotilédones, dura, em média, de quatro a dez dias, podendo prolongar-se em condições desfavoráveis. Na segunda fase surge o primeiro botão floral que, geralmente, acontece aos 30 dias após a emergência (DAE). A terceira fase caracteriza-se pelo aparecimento da primeira flor, que ocorre ente os 45 e $60 \mathrm{DAE}$. Já na quarta fase, dá-se a abertura do primeiro capulho, entre os 90 e 120 DAE e, finalmente, a quinta fase inclui as primeiras e últimas colheitas, quando as maçãs estão completamente abertas, o que ocorre, em média entre os 120 DAE, dependendo da cultivar e do ambiente (Beltrão \& Souza, 2001).

Chiavegato (1995), citando outros autores, faz referência que o hábito indeterminado de crescimento do algodoeiro torna-o morfologicamente complexo, uma vez que os desenvolvimentos vegetativo e reprodutivo ocorrem simultaneamente. Deste modo, é considerável o efeito que o ambiente exerce não só sobre o crescimento vegetativo dessa planta como também nos componentes da produção e na qualidade da fibra. Chiavegato (1995) estudando o efeito do ambiente e de cultivares nos componentes da produção e nas características tecnológicas da fibra e do fio de algodão, concluiu que a influência do ambiente nas características estudadas (produção, massa de 
capulho, massa das sementes, porcentagem de fibra, comprimento da fibra e as características tecnológicas da fibra e do fio) foi, em geral, maior à de cultivar. Consequentemente, torna-se imprevisível a pré-determinação de valores destas características. Ainda segundo o autor, as melhorias do ambiente, exclusivamente para a produção de algodão, não resultam necessariamente em melhorias na qualidade da fibra e do fio. Assim, como a melhoria do ambiente não garante a capacidade genética das cultivares para a qualidade da fibra, algumas cultivares mostram-se mais sensíveis a condições desfavoráveis.

\subsection{Cultivares}

As mudanças no sistema de produção para áreas extensas e com o uso intensivo de mecanização e insumos têm levado os pesquisadores a buscar uma maior diversificação de cultivares. O melhoramento genético no Brasil sempre foi direcionado visando atender os interesses dos produtores, beneficiadores e também à indústria têxtil. Desta maneira, sempre se objetivou a obtenção de cultivares produtivas, com resistência múltipla a doenças, pragas e a outros fatores de ambiente, com bom rendimento em fibra e características tecnológicas da fibra compatíveis com as exigências da indústria têxtil (Carvalho, 1999).

A arquitetura das plantas do algodoeiro também evoluiu neste processo de melhoramento, passando dos tipos piramidais ou cônicos, para plantas mais "cilíndricas", compactas e com maturação mais uniforme, adaptadas às novas tecnologias. Como exemplo de cultivar de forma cilíndrica temos o CD 401 da empresa Coodetec/Cirad, que é uma cultivar de ciclo precoce, do grupo de materiais "determinados", ramos frutíferos curtos, moderada exigência em reguladores de crescimento, adaptada à colheita mecânica, apresenta fibras de alta qualidade (Penna et al. 2001). A cultivar DeltaOpal é uma cultivar de porte médio, com ramos frutíferos 
curtos, ciclo normal semi-determinado, com exigência moderada em regulador de crescimento (Ornellas et al., 2001).

Penna et al. (2001) menciona ainda que doenças antes tidas como ocasionais, tornaram-se problemas no presente, trazendo grandes desafios aos melhoristas. Em geral, dentre as cultivares desenvolvidas no Brasil, a cultivar IAC 23 lançada no ano agrícola de 2000/01 pelo Instituto Agronômico de Campinas, não se enquadra no novo modelo de arquitetura, apresentando plantas do tipo tradicional, ciclo longo, vigorosa, que necessita rigoroso manejo da altura com regulador de crescimento para adaptação à colheita mecânica. Porém é uma cultivar que apresenta resistência múltipla a doenças.

Com as diferenciações no sistema de produção e também nos processos de fiação, aumentou a demanda por cultivares em atender a essas mudanças. Todavia, com a entrada de novas cultivares no mercado há a necessidade de se rever as formas de manejo destes materiais, que apresentam características distintas de crescimento, desenvolvimento e exigência nutricional, entre inúmeros outros fatores.

\subsection{Espaçamento}

A população ideal de uma cultura por unidade de área, é um dos

componentes da produção que mais contribui no aumento da produtividade final (Holliday, 1960). A adequação da população de plantas destaca-se por se tratar de uma técnica de baixo custo e relativamente simples. Porém, apesar de simples, ela é influenciada por vários fatores, dentre eles o porte da cultivar, a fertilidade do solo e as técnicas de manejo (Righi et al., 1965; Passos, 1977; Laca-Buendia \& Farias, 1982; Bolonhezi, 1997).

De acordo com Lamas \& Staut (2001), a resposta do algodoeiro em relação à população de plantas por área é complexa e envolve aspectos ecofisiológicos, pois, alterações no espaçamento e na densidade induzem a uma série de modificações no 
crescimento e desenvolvimento do algodoeiro. Segundo estes autores a altura de plantas, o diâmetro da haste principal, a altura de inserção do primeiro ramo frutífero, o número de ramos vegetativos e reprodutivos são algumas das características morfológicas do algodoeiro significativamente influenciadas pela população de plantas.

Para Hearn (1971), quando as condições de clima e solo são favoráveis, os espaçamentos mais largos entre fileiras, como por exemplo 1,0 m, são melhores que os mais estreitos devido à possibilidade de se obter maior produtividade em função de um maior desenvolvimento vegetativo e reprodutivo das plantas. Nas condições do Estado de São Paulo, conforme Righi et al. (1965), Passos (1977) e Gridi-Papp et al. (1992), a distância entre fileiras não vai além de 1,00 m, ficando entre 0,80 - 0,90 m nas terras de fertilidade média e 0,60 - 0,70 m nas mais fracas, com 5 a 10 plantas por metro. Citam, ainda, que os espaçamentos mais convenientes são aqueles que correspondem a cerca de $2 / 3$ da altura média das plantas e que as folhas das plantas devem cobrir toda a superfície do solo entre as fileiras na época do máximo florescimento, sem haver entrelaçamento entre elas.

Jones \& Wells (1997) em estudos realizados nos Estados Unidos concluíram que a variação do número de plantas na linha de semeadura influenciou nas características tecnológicas da fibra enquanto a produção de algodão foi mais influenciada pelo espaçamento entre fileiras. Thompson (1999) recomenda para os Estados Unidos nos espaçamentos de $0,96 \mathrm{~m}$, densidade de semeadura de 6 a 9 plantas por metro. Sendo que para os espaçamento de $0,76 \mathrm{~m}$ a recomendação é similar, podendo-se obter aumentos de 10 a $15 \%$ no rendimento da cultura, para este espaçamento.

É importante salientar que, na determinação de dado espaçamento, devem-se levar em consideração aspectos culturais, como cultivos e colheita. Se a colheita é feita mecanicamente, o espaçamento entre fileiras deverá ser adequada às características da colhedora (Banci, 1992), pois, a população de plantas de algodoeiro, por unidade de área, influencia, como já citado, nas características agronômicas da planta. Assim, a população ideal deverá ser determinada não só em função do 
rendimento, mas também tendo em vista a adaptação estrutural da comunidade vegetal à colheita mecânica.

Mohamed et al. (1982), estudando quatro genótipos de algodoeiro em diferentes espaçamentos entre fileiras, concluíram que diferentes genótipos respondem de maneira diferente aos vários espaçamentos estudados. Sugerindo desta forma que a determinação do espaçamento entre fileiras, deverá ser adequado às características de crescimento e desenvolvimento dos genótipos. Observaram também que o aumento da população de plantas por área apresenta limites, sobretudo quanto aos genótipos utilizados.

Kittock et al. (1986), em pesquisa realizada no Arizona durante cinco anos, concluíram que a redução na altura das plantas pelo aumento da população devese à redução na densidade do fluxo da radiação luminosa ao longo do dossel da cultura. O aumento na população contribui para a redução da densidade do fluxo radiante, diminuindo a fotossíntese, o que leva a grande abscisão de flores e frutos. Desta forma sugerem que a competição por água e nutrientes, assim como a alteração do microclima, não deverá ser de grande importância para a cultura.

Yamaoka et al. (1982), estudando a densidade de plantas de algodoeiro sobre a inserção de ramos frutíferos, com a finalidade de adaptação das plantas à colheita mecânica, observaram que a altura da inserção dos primeiros ramos produtivos foi elevada pela redução do espaçamento. Porém, o aumento excessivo da população pode ter efeito negativo sobre a produção.

Outros pesquisadores, como Williford et al. (1986) e Heitholt et al. (1996), buscavam, através da redução do espaçamento entre fileiras melhorar a intercepção da radiação solar, diminuir a evaporação da água no solo e controlar plantas daninhas e pragas. Porém, não observaram diferenças significativas no rendimento de fibras no espaçamento de $0,76 \mathrm{~m}$ em relação ao espaçamento de $1,02 \mathrm{~m}$ entre fileiras.

Grande volume de trabalhos com distribuição espacial de plantas de algodoeiro por área são realizados nos Estados Unidos onde vêm se procurando alternativas de baixo custo para aumento da produtividade. Uma das alternativas promissoras é o cultivo do algodão "ultra-narrow row" (espaçamento entre linhas ultra 
adensados, 0,25 m) com altas populações de plantas por área. Trabalhos realizados por Maas et al. (1997), Cawley et al. (1998), Jost et al. (1998), Allen et al. (1998) e Gerik et al. (1998) demostraram a eficiência deste sistema de cultivo na precocidade de colheita, redução de perdas com a extensão da época das colheitas, diminuição dos custos com inseticidas, herbicidas e reguladores de crescimento e aumento de produtividade em alguns casos. Estes estudos ainda são preliminares e adaptam-se à nova proposta de mudança do sistema de produção de algodão nos Estados Unidos.

No Texas, avaliando as cultivares Paymaster 101 a e C.A. 491 nos espaçamentos entre plantas de 0,$127 ; 0,178 ; 0,254 ; 0,356$ e $0,508 \mathrm{~m}$, com populações de 38.750 a 620.000 plantas por hectare, mantendo o mesmo espaçamento entre linhas e entre plantas nas linhas, Fowler \& Ray (1977) obtiveram altas produções de fibras nos espaçamentos de 0,234 e 0,356 m para ambas as cultivares. A cultivar Paymaster 101, no entanto, também apresentou bom rendimento de fibra no espaçamento de $0,508 \mathrm{~m}$. A altura de plantas, diâmetro do caule, número de ramos vegetativos e frutíferos aumentaram com o aumento de espaçamento entre plantas. A massa do capulho, massa de 100 sementes e porcentagem de fibra sofreram redução quando os espaçamentos entre plantas decresceram. Quanto às características da fibra, somente a finura foi reduzida em alta densidade populacional, as demais características, comprimento e resistência da fibra, não sofreram efeitos significativos.

Jost \& Cothren (2000 e 2001) comparando o efeito de espaçamentos super adensados com o sistema convencional de semeadura na cultivar 'Stoneville BXN47' durante três anos de cultivo, nos Estados Unidos, concluíram que nos tratamentos super adensados $(0,19$ e $0,38 \mathrm{~m})$ em anos com baixa precipitação o rendimento de fibra foi superior ao do sistema convencional $(0,76$ e $1,01 \mathrm{~m})$, não observando diferenças entre espaçamentos de 0,76 e 1,01 m, nestas condições. Em condições normais de precipitação não foram observadas diferenças nas médias de produtividade nos ensaios realizados.

No Brasil, a partir dos anos 60, vários trabalhos sobre população de planta e espaçamentos em algodoeiro, foram realizados, como citam Belletini (1988), Lamas (1988), Banci (1992) e Souza (1996). 
Nobrega et al. (1993) em condição irrigada no estado da Paraíba, estudando diferentes arranjo de plantas com a cultivar CNPA Precoce 1, obtiveram médias de 19, 35 e 24, $89 \%$ a mais na produtividade nas configurações $0,50 \mathrm{~m}$ x 0,40m e $1,7 \mathrm{~m} \times 0,30 \mathrm{~m} \times 0,20 \mathrm{~m}$, respectivamente, do que na configuração tradicionalmente recomendada, de $1,00 \mathrm{~m}$ entre fileiras e $0,20 \mathrm{~m}$ entre plantas. A massa do capulho, massa de 100 sementes, porcentagem de fibra e características tecnológicas da fibra, não foram alterados pelos fatores estudados.

Bellettini (1988), estudando no norte do Paraná, o efeito da semeadura do algodoeiro (cultivar IAC 20) em linhas simples com espaçamentos de 0,8;0,9 e 1,0 m e em linhas duplas de $0,4 \times 1,2 ; 0,4 \times 1,4$ e $0,5 \times 1,5 \mathrm{~m}$, com variação do número de plantas por metro linear de 5, 7 e 10, observou que a cultivar utilizada comportou-se, no que se refere à produção e qualidade de fibra, igualmente em qualquer dos sistemas de semeadura utilizadas.

Souza (1996), avaliando o comportamento da cultivar CPNA - 7H em Viçosa, nos espaçamentos que variaram de 0,4 à $1,0 \mathrm{~m}$ e com diferentes densidade de plantas/m, observou que não houve alteração da produção em função do espaçamento e da densidade de plantas. Os tratamentos não influenciaram o caráter precocidade de colheita e as características de uniformidade de comprimento, resistência da fibra e grau de amarelecimento. As características do caule, número de ramos frutíferos por planta, número de capulhos por plantas e massa de capulhos foram determinantes no aumento da produção por planta em função da variação da população de plantas por área.

Em ensaios conduzidos em Minas Gerais, Lamas et al. (1989), estudando a interação de espaçamentos entre fileiras e época de semeadura na cultura do algodoeiro (cultivar IAC 20), constatou que na variação do espaçamento de 0,3 à 1,20 m, a redução do espaçamento entre fileiras promoveu aumento na altura de inserção do primeiro ramo frutífero e redução na altura das plantas, no diâmetro do caule, no número de capulhos por planta, no massa de capulhos e no massa de 100 sementes. Para a produção de algodão em caroço, independente da época de semeadura, foram melhores os espaçamentos de 0,6 e $1,00 \mathrm{~m}$. 
Carvalho et al. (2001b) em trabalho realizado com três cultivares (IAC 19, IAC 20 e CNPA Precoce 1) avaliando dois espaçamentos (0,60 e 0,90m) e uso de regulador de crescimento, no Estado de São Paulo, concluíram que em espaçamento mais denso (espaçamento de 0,60m), aumento a produtividade, a despeito da menor massa de capulho por planta. A aplicação de regulador de crescimento proporcionou aumentos na produtividade, na massa de 100 sementes, além de aumentar o comprimento, o índice micronaire e a tenacidade da fibra. Em contra partida, concorreu para diminuir a altura das plantas, o número de capulhos por planta e a porcentagem de fibra.

Carvalho et al. (2001a), também no Estado de São Paulo estudando a cultivar IAC 23 em diferentes espaçamentos $(0,76$ e $0,95 \mathrm{~m})$ e densidade de plantas (5, 8, 11, e 14 plantas por metro linear), observaram aumento na altura das plantas no espaçamento maior, mesmo não apresentando diferenças na produtividade. A densidade de 11 plantas por metro linear, independente do espaçamento utilizado, proporcionou aumento na produtividade.

\subsection{Reguladores de crescimento}

A aplicação de reguladores de crescimento em algodoeiro tem assumido destaque especial dentre as técnicas culturais, devido à possibilidade de controlar o desenvolvimento das plantas em solos de fertilidades variáveis, visando melhorar as condições de cultivo, facilitar a utilização de defensivos e a mecanização da colheita (Barbosa \& Castro, 1984).

As cultivares de algodoeiro herbáceo de porte alto e ciclo longo, quando

estabelecidas em solos de alta fertilidade e de fatores climáticos favoráveis, apresentam um desenvolvimento vegetativo intenso, promovendo o sombreamento do baixeiro, apodrecimento de maçãs, concentração de carga no ponteiro causando tombamento das 
plantas, ineficiência no controle de pragas, dificuldade na colheita mecânica e consequentemente perda de tipo e qualidade da fibra (Gridi-Papp et al., 1992).

Weaver (1976) já salientava a crescente necessidade de minimizar o crescimento de algumas plantas, levando ao retardamento geral do crescimento ou ainda mantendo um certo nível de crescimento. Os reguladores de crescimento, que são hormônios produzidos na planta ou sintetizados destas, podem controlar este índice de crescimento vegetativo.

Sendo o algodoeiro uma planta naturalmente de crescimento indeterminado, ocorre competição por assimilados entre drenos reprodutivos, onde se localiza a parte econômica da planta, (fibras + sementes) e drenos vegetativos, englobando raízes, caule, folhas novas etc. Para que se tenha produtividades elevadas, deve-se estabelecer um maior equilíbrio entre o crescimento (aumento irreversível de fitomassa) e o desenvolvimento desta planta (Nóbrega et al. 1999).

Vários trabalhos comprovam a capacidade dos reguladores de crescimento em reduzir o porte das plantas (Barbosa, 1983; Stuart et al., 1984; Barbosa e Castro, 1984; Laca-Buendia, 1989; Reddy et al., 1990; Athayde \& Lamas, 1999; Soares, 1999; Lamas et al., 2000).

Com a utilização de substâncias que interferem no crescimento das plantas, é possível que se tenha uma relação mais equilibrada entre a parte reprodutiva e vegetativa. De acordo com Zhao e Oosterhuis (1998), os efeitos dos reguladores de crescimento sobre o algodoeiro são dependentes das condições climáticas.

Os reguladores de crescimento quando bem utilizados promovem a redução do porte da planta e aumentam a produção de algodão em caroço (Bolonhezi, 1997). Lamas (1997) também constatou que a utilização de reguladores de crescimento proporcionam redução na altura das plantas e no tamanho dos ramos laterais, permitindo melhores condições de cultivo, aumentando a precocidade e favorecendo o desempenho da colheita, principalmente a mecanizada.

Santos (1998) propõe que com o surgimento de novas cultivares, da utilização de semeadura adensado e adequação da cultura à colheita mecânica, tornou-se imprescindível, em muitas lavouras, o uso de redutores de crescimento. O uso do 
regulador de crescimento, segundo o autor, é também utilizado para adequar as plantas às pulverizações para controle de pragas e doenças e proporcionar maior precocidade do algodoeiro. Ou seja, o redutor de crescimento uniformiza o crescimento da planta facilitando a penetração da calda no interior da vegetação melhorando a eficiência de controle de pragas e doenças.

York (1983), na Carolina do Norte, estudando durante três anos o efeito do cloreto de mepiquat em quatorze cultivares de algodão, constatou que as cultivares respondem de forma diferente a este produto, não se observando também as mesmas respostas nos diferentes anos de cultivos.

Cia et al. (1996) analisando a densidade de semeadura associada ao uso de regulador de crescimento na cultivar IAC 18 em diferentes localidades, constatou que as plantas apresentaram portes variados nos ensaios realizados. Onde o porte das plantas foi mais elevado $(>1,40 \mathrm{~m})$, a produção foi menor nas maiores densidades de semeadura (16 plantas/m) e o regulador promoveu aumento significativo na produção. Em plantas pouco desenvolvidas, a produção foi menos afetada pela densidade de semeadura e não houve efeito do regulador de crescimento. $\mathrm{O}$ regulador de crescimento ocasionou diminuição na altura das plantas, aumento no número de capulhos localizados na parte inferior da planta, diminuição no número de carimãs (capulhos "mal-abertos") e aumento da precocidade.

Quando se comparou o efeito do regulador de crescimento aplicado nas cultivares IAC 19 e IAC 20, que possuem características de porte e ciclo decrescente nesta ordem, observou-se que o bioregulador provocou uma redução de porte de $13 \%$ em relação à testemunha, sendo este efeito mais expressivo na cultivar de maior porte. Quanto a produtividade, o efeito do tratamento só foi visualizado na cultivar IAC 19, com beneficio de 20 arrobas por hectare de algodão em caroço (Santos et al., 1988).

Banci (1992), em Viçosa, estudando os efeitos de quatro espaçamentos entre fileiras $(0,40 ; 0,60 ; 0,80$; e 1,00 m), combinados com quatro doses de cloreto de mepiquat $\left(0,0 ; 0,5 ; 1,0 ;\right.$ e $\left.1,051 . h^{-1}\right)$, em quatro épocas de semeadura, observou que, com a redução no espaçamento entre fileiras, houve diminuição no crescimento das plantas e aumento da inserção do primeiro ramo produtivo. Ainda, com a aplicação de 
cloreto de mepiquat, houve também diminuição no crescimento das plantas e aumento na massa de cem sementes. Não influenciando, porém, os parâmetros produtivos e a qualidade tecnológica da fibra.

Para a tomada de decisão sobre a aplicação de regulador de crescimento, deve se levar em consideração as características genéticas da cultivar, fertilidade do solo, condições climáticas, população de plantas e época de semeadura, sendo, evidentemente, recomendada a aplicação somente em condições favoráveis ao crescimento e desenvolvimento das plantas. Lamas (2001) recomenda a dose de 1,0 1.ha ${ }^{-1}$ de cloreto de mepiquat, aplicada de forma parcelada. Em condições favoráveis de crescimento vegetativo e para cultivares de porte alto pode ser necessária a aplicação de doses maiores as quais deverão ser definidas tendo-se como referencial o crescimento das plantas e não somente o estádio fenológico. Assim, é indispensável o monitoramento do crescimento das mesmas. 


\section{MATERIAL E MÉTODOS}

\subsection{Local e Período da Experimentação}

O experimento foi conduzido na área experimental da Escola Superior de Agricultura "Luiz de Queiroz" (ESALQ/USP), no município de Piracicaba, Estado de São Paulo, localizado a $22^{\circ} 41^{\prime} 30^{\prime \prime}$ de longitude Oeste e $546 \mathrm{~m}$ de altitude, durante o período de outubro de 2000 a maio de 2001.

\subsection{Elementos de Clima}

Os dados climatológicos de precipitação pluvial, temperatura máxima, mínima e média, umidade relativa do ar, radiação solar e insolação, registrados no período de outubro de 2000 a abril de 2001, foram obtido através do Posto Agrometeorológico do Departamento de Ciências Exatas da ESALQ/USP, e podem ser observados nas figuras de 1 a 7 (em anexo). 


\subsection{Características do solo}

Os resultados da análise química do solo, classificado como Terra Roxa Estruturada Eutrófica, na profundidade de 0-20 cm, foram obtidas pelo Laboratório de Análises Química do solo, do Departamento de Solos e Nutrição de Plantas da ESALQ/USP e encontram-se nas tabelas 1 e 2.

Tabela 1. Resultados da análise química do solo da área experimental, na profundidade de 0-20 cm. Piracicaba - SP.

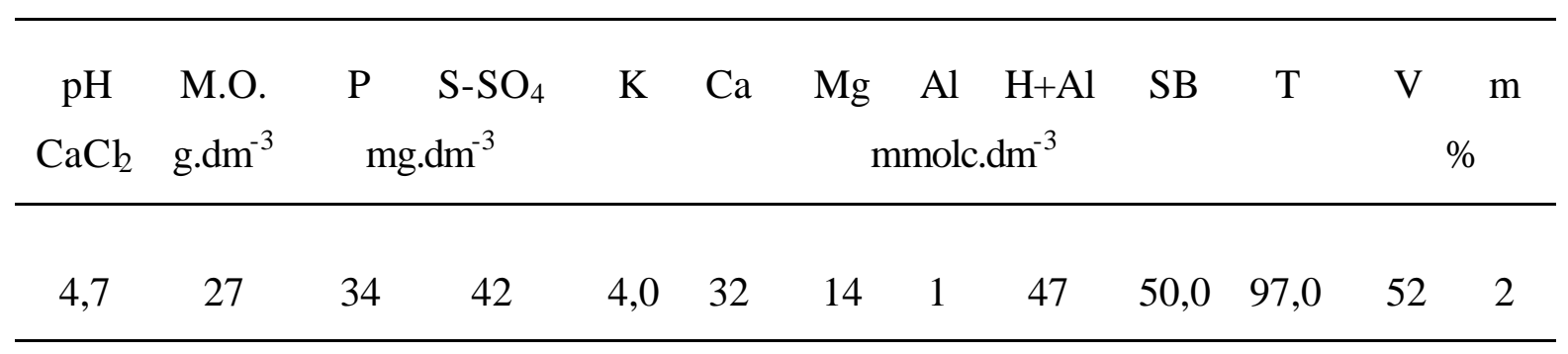

Tabela 2. Resultados da análise química do solo da área experimental, na profundidade de 0-20 cm. Piracicaba - SP.

\begin{tabular}{ccccc}
\hline $\mathrm{B}$ & $\mathrm{Cu}$ & $\begin{array}{c}\mathrm{Fe} \\
\mathrm{mg} \cdot \mathrm{dm}^{-3}\end{array}$ & $\mathrm{Mn}$ & $\mathrm{Zn}$ \\
\hline 0,24 & 4,3 & 21 & 20,6 & 1,7 \\
\hline
\end{tabular}




\subsection{Delineamento Experimental}

O delineamento experimental adotado foi o de blocos ao acaso com parcelas subsubdivididas, com 4 repetições. As parcelas constituíram-se dos espaçamentos (E), as subparcelas das cultivares (V) e as sub-subparcelas do regulador de crescimento $(\mathrm{R})$. Os espaçamentos adotados nas parcelas foram de 0,76 e 1,01 m. Nas subparcelas os tratamentos foram constituídos por três cultivares de algodoeiro com arquiteturas típicas e representativas das características das cultivares disponíveis na cotonicultura brasileira, ou seja:

a) IAC 23 - forma cônica, porte alto, desenvolvimento vegetativo vigoroso, ramos frutíferos longos, ciclo longo indeterminado e frutos grandes (tipo padrão de plantas das cultivares paulistas) (Penna et al. 2001);

b) DeltaOpal - forma cilíndrica, porte alto, desenvolvimento vegetativo vigoroso, ramos frutíferos mediamente curto, (semi-cluster) ciclo médio semi-determinado e frutos médios (Ornellas et al., 2001);

c) CD 401 - forma cilíndrica, porte médio, desenvolvimento vegetativo pouco vigoroso, ramos frutíferos curtos (semi-cluster), ciclo precoce semi-determinado e frutos médios (Penna et al. 2001).

Nas sub-subparcelas as cultivares foram avaliadas na ausência e presença de regulador de crescimento (cloreto de mepiquat), sendo que nos tratamentos com regulador de crescimento as aplicações foram realizadas em função do monitoramento através de medições periódicas da altura das plantas, de modo que estas não ultrapassassem 1,20 $\mathrm{m}$ de altura.

As parcelas com espaçamento de $0,76 \mathrm{~m}$ foram constituídas por 6 linhas

de $5 \mathrm{~m}$ de comprimento, considerando-se úteis as quatro linhas centrais, $15 \mathrm{~m} 2 /$ parcela. No espaçamento de 1,01 $\mathrm{m}$ foram mantidas 5 linhas de 5 metros de comprimento, considerando-se úteis as 3 linhas centrais, $15 \mathrm{~m}^{2} /$ parcela. Uma linha marginal externa foi semeada em cada lado e em toda a extensão do experimento. 


\subsection{Condução do experimento}

O experimento foi instalado no dia 09 novembro de 2000. Anteriormente a instalação do experimento, o solo foi preparado de maneira convencional utilizando-se uma aração e duas gradeações para destorroamento, nivelamento e incorporação de herbicida (Trifluralina, 1,8 1.ha ${ }^{-1}$ para o controle de gramíneas anuais).

Os sulcos de semeadura foram abertos com auxílio de enxadas, conforme o espaçamento adotado $(0,76 \mathrm{~m}$ ou $1,01 \mathrm{~m})$ e na profundidade aproximada de $0,05 \mathrm{~m}$.

A distribuição das sementes foi realizada manualmente, utilizando-se cerca de 50 sementes por metro linear o que garantiu um estande definitivo de 8 plantas por metro linear. O ajuste do estande pelo desbaste ocorreu aos 27 dias após a emergência (DAE) das plântulas.

A adubação de semeadura foi calculada em função da análise química do solo. Utilizou-se na adubação de semeadura: $15 \mathrm{~kg}$ de $\mathrm{N}, 80 \mathrm{~kg}$ de $\mathrm{P}_{2} \mathrm{O}_{5}, 60 \mathrm{~kg}$ de $\mathrm{K}_{2} \mathrm{O}$ e $1 \mathrm{~kg}$ de B por hectare, conforme Silva e Raij (1996). Como fontes dos nutrientes N, P e K foram utilizados uréia, superfosfato simples e o cloreto de potássio, respectivamente.

Para adubação nitrogenada em cobertura foi utilizada uréia como fonte de $\mathrm{N}$, aplicando-se $40 \mathrm{~kg}$ de $\mathrm{N}$ por hectare aos $28 \mathrm{DAE}$ e $20 \mathrm{~kg}$ de $\mathrm{N}$ por hectare aos 41 DAE, coincidindo com o início do florescimento. A adubação foi realizada colocando-se o adubo em linha contínua próximo das plantas e incorporado, segundo recomendações de Silva e Raij (1996).

O controle das plantas daninhas durante a condução do experimento foi efetuado através de capinas manuais, durante os primeiros meses de desenvolvimento da cultura. As plantas que surgiram posteriormente foram eliminadas manualmente.

O controle de pragas foi realizado de acordo com as necessidades da cultura e teve caráter preventivo. As aplicações visaram ao controle do bicudo (Anthonomus grandis Boh.), ácaro branco (Polyphagotarsonemus latus Banks), ácaro rajado (Tetranychus urticae Koch), pulgão (Apis gossypii Glov.) e percevejo rajado (Horcias nobilellus Berg.), perfazendo o total de dez aplicações. 
O regulador de crescimento utilizado para controle da altura das plantas foi o produto comercial PIX que contém 5\% de cloreto de mepiquat, aplicado com pulverizador costal de $\mathrm{CO}_{2}$ com pressão constante e bico cônico X2. As doses do produto foram estabelecidas mediante o monitoramento periódico da altura das plantas nos tratamentos com regulador de crescimento, respeitando-se as características de crescimento de cada cultivar e a altura final desejada em cada espaçamento. Para a cultivar IAC 23, nas parcelas referentes ao tratamento com regulador, foi aplicado 600 $\mathrm{ml}^{-1} \mathrm{a}^{-1}$ de PIX de forma parcelada, $300 \mathrm{ml}^{-h a^{-1}}$ na primeira aplicação e $300 \mathrm{ml}^{-h^{-1}}$ na segunda, aos 48 e 87 DAE, respectivamente. Para a altivar DeltaOpal foi aplicado 450 ml.ha ${ }^{-1}$ de PIX, também de forma parcelada sendo $150 \mathrm{ml}^{-h^{-1}}$ aos 48 DAE e $300 \mathrm{ml}^{-\mathrm{ha}^{-1}}$ aos 87 DAE. A cultivar CD 401 teve o tratamento de regulador de crescimento diferenciado também em função do espaçamento. Nas parcelas com espaçamento de 0,76 m entre fileiras a dose de PIX foi de $600 \mathrm{ml}^{-h^{-1}}$, sendo $300 \mathrm{ml} \cdot \mathrm{ha}^{-1}$ aos 73 e 300 $\mathrm{ml}^{-1} \mathrm{~h}^{-1}$ aos 87 DAE. Nas parcelas com espaçamento de 1,01 m entre fileiras aplicou-se 450 ml.ha ${ }^{-1}$ de PIX, $150 \mathrm{ml}^{\circ} \mathrm{ha}^{-1}$ e $300 \mathrm{ml}^{-h^{-1}}{ }^{\text {, aos }} 73$ e 87 DAE, respectivamente.

A colheita foi realizada manualmente em várias etapas para determinação da precocidade das cultivares, iniciando-se após a abertura das primeiras maçãs. Para a cultivar CD 401 realizaram-se 5 colheitas sendo a primeira aos 132 DAE e as demais aos 139, 145, 153 e 160 DAE. Na cultivar DeltaOpal foram realizadas 4 colheitas, a primeira aos 139 DAE e as demais aos 145, 153 e 160 DAE. Na cultivar IAC 23 a primeira colheita ocorreu aos 145 DAE e as demais aos 153, 160 e 168 DAE. Na área útil de cada parcela foi colhida aleatoriamente uma amostra de 20 capulhos no terço médio superior das plantas para análises posteriores das características agronômicas e tecnológicas da fibra. 


\subsection{Acompanhamento fenológico}

Os estádios fenológicos foram determinados a partir dos seguintes eventos: semeadura a emergência, emergência ao aparecimento do primeiro botão floral, emergência a antese da primeira flor, emergência ao primeiro capulho e completa maturação (80\% de capulhos). As determinações foram realizadas em 6 plantas previamente marcadas aleatoriamente e localizadas nas linhas úteis de cada parcela. Foram anotadas as datas de ocorrência dos eventos, para determinar o número de dias para cada fase de crescimento, e desenvolvimento das plantas.

A unidade de calor foi calculada considerando a temperatura base de $15^{\circ} \mathrm{C}$ (Rosolem, 2001) e aplicando-se a seguinte fórmula de acordo com Oosterhuis (1999):

Onde:

$$
\mathrm{UC}=[(\mathrm{T}+\mathrm{t}) / 2]-15
$$

$$
\begin{aligned}
& \text { UC = Unidades de calor acumulada } \\
& \mathrm{T}=\text { Temperatura máxima diária } \\
& \mathrm{t}=\text { Temperatura mínima diária } \\
& 15=\left({ }^{\circ} \mathrm{C}\right) \text {, temperatura base }
\end{aligned}
$$

\subsection{Variáveis analisadas}

\subsubsection{Produção e Precocidade de colheita}

A produção foi determinada através da massa, em quilogramas, de algodão em caroço, produzido nas linhas úteis de cada parcela experimental (área útil de cada parcela $15 \mathrm{~m}^{2} /$ parcela). Os dados foram transformados em quilogramas por hectare. 
A precocidade de colheita foi calculada considerando-se a massa da primeira colheita $(\mathrm{kg})$ em relação à massa da colheita total $(\mathrm{kg})$ da área útil, representando-se, assim, o índice de precocidade, em porcentagem.

\subsubsection{Caracteres agronômicos de campo}

Os caracteres agronômicos de campo foram determinados por ocasião da primeira colheita aos 130 DAE em 6 plantas aleatoriamente marcadas previamente em cada parcela, nas quais foram efetuadas as seguintes avaliações:

- Altura de planta: Para esta determinação foi tomada a altura em centímetros, da distância entre o nó cotiledonar e a gema apical, com o auxílio de uma régua graduada. As alturas das plantas foram anotadas antes da aplicação do regulador de crescimento (45, 75 e 90 DAE) e por ocasião da primeira colheita (130 DAE).

- Diâmetro do caule: Determinado com o auxílio de paquímetro, a um centímetro acima do nível solo.

- Número de ramos vegetativos e frutíferos: Realizaram-se a contagem dos números de ramos vegetativos e de ramos frutíferos por plantas.

- Conformação da planta: Em três partes das plantas, ou seja, inferior, mediana e superior foram medidos os comprimentos dos ramos frutíferos para determinação da conformação das plantas.

- Número médio de capulhos por planta: Foi contado o total de capulhos produzidos pelas 6 plantas de cada parcela, determinando-se o número médio de capulhos por plantas.

- Altura de inserção do primeiro ramo frutífero: Foi determinada, em centímetros, a distância entre o nó cotiledonar e a inserção do primeiro ramo frutífero, com o auxílio de uma régua graduada. 


\subsubsection{Caracteres agronômicos de laboratório}

A partir da amostra aleatória de 20 capulhos foram determinadas:

- Massa de 100 sementes: Massa média, em gramas de 100 sementes.

- Porcentagem de fibra: A porcentagem de fibra foi determinada por diferença a partir da massa das sementes (g) e expressa em porcentagem.

- Massa média de um capulho: Correspondendo à média da massa dos capulhos, em gramas.

\subsubsection{Características tecnológicas da fibra}

Durante a colheita da área útil das parcelas foram retiradas amostra de 20 capulhos por parcela, colhidos aleatoriamente no terço médio superior da planta, para análise das características tecnológicas da fibra. As amostras foram enviadas ao Laboratório de Tecnologia de Fibras do Centro de Algodão e Fibrosas Diversas do Instituto Agronômico de Campinas, onde foram analisadas as seguintes características:

- Comprimento da fibra: Valor médio, em milímetros, do comprimento "span 2,5\%", determinado pelo HVI (high volume instument). Foi obtido a partir de cinco determinações feitas em cada amostra.

- Uniformidade de Comprimento: Valor médio, em porcentagem, da uniformidade do comprimento das fibras, baseado na relação dos valores de comprimento "span 50\%"e "span25\%", fornecidos pelo HVI, a partir de cindo determinações feitas em cada amostra.

- Maturidade: Valor médio referente a porcentagem de fibras maduras, determinado no HVI. Foi obtido a partir de cinco determinação feitas na amostra.

- Tenacidade: Índice médio referente à resistência à tração de uma mecha de fibras, expresso em gf/Tex, determinado no HVI. Foi obtido mediante quatro determinações em cada amostra. 
- Índice Micronaire: Índice determinado no HVI, e que representa a finura da fibra, quando são iguais as condições de maturidade. Em nosso meio representa mais comumente o complexo finura + maturidade, quando ambas as propriedades variam. Foi obtido mediante duas determinação de cada amostra.

\subsection{Análise estatística}

Os dados obtidos das variáveis estudadas foram submetidos às análises de variância aplicando-se teste $\mathrm{F}$, e quando houve diferença entre as médias, estas foram comparadas pelo teste de Tukey a 5\% de probabilidade, conforme Gomes (1990). A análise de variância foi obtida conforme o esquema do tabela 3 .

Tabela 3. Esquema da análise de variância para os dados das variáveis estudadas.

\begin{tabular}{lr}
\hline Causas da Variação & G.L. \\
\hline Bloco (B) & 3 \\
Espaçamento (E) & 1 \\
Resíduo (A) & 3 \\
(Parcelas) & $(7)$ \\
Cultivar (V) & 2 \\
Interação ExV & 2 \\
Resíduo (B) & 12 \\
(Subparcelas) & $(23)$ \\
Regulador (R) & 1 \\
Interação ExR & 1 \\
Interação VxR & 2 \\
Interação ExVxR & 2 \\
Resíduo (C) & 18 \\
(Sub-subparcelas) & $(47)$ \\
\hline
\end{tabular}




\section{RESULTADOS E DISCUSSÃO}

\subsection{Acompanhamento Fenológico}

A determinação dos estádios de crescimento de cada cultivar é muito importante para o manejo adequado da cultura. O número de dias necessários assim como a unidade de calor (UC) para cada estádio do ciclo de crescimento de cada cultivar, nas condições em que o experimento foi instalado, encontram-se na tabela 4 .

Tabela 4. Número médio de dias e unidades de calor (UC) para as cultivares IAC 23, DeltaOpal e CD 401 obtidos durante as fases de crescimento da cultura. Ano agrícola 2000/01. Piracicaba, SP.

\begin{tabular}{|c|c|c|c|c|c|c|}
\hline \multirow{2}{*}{ Estádio de Crescimento } & \multicolumn{3}{|c|}{ Número de dias } & \multicolumn{2}{|c|}{ Unidade calor } & \multirow[b]{2}{*}{ CD 401} \\
\hline & IAC 23 & DeltaOpal & CD 401 & IAC 23 & DeltaOpal & \\
\hline Semeadura a emergência & 7 & 7 & 7 & 58,5 & 58,5 & 58,5 \\
\hline Emergência ao $1^{0}$ botão floral & 41 & 41 & 41 & 356,7 & 356,7 & 356,7 \\
\hline Emergência a antese da $1^{\text {a flor }}$ & 61 & 60 & 58 & 562,3 & 549,9 & 526,0 \\
\hline Emergência ao $1^{\circ}$ capulho & 125 & 124 & 117 & 1246,2 & 1235,1 & 1170,0 \\
\hline Emergência a colheita & 145 & 139 & 132 & 1460,2 & 1404,4 & 1325,4 \\
\hline
\end{tabular}


Os dados observados na fase de emergência estão de acordo com Rosolem (2001) que, citando outros autores, comenta que a velocidade de emergência depende fundamentalmente da temperatura e em condições normais ocorre entre 5 a 10 dias com a necessidade de unidades de calor (UC) em torno de 50-60.

O período entre a emergência das plântulas ao primeiro botão floral pode demorar de 27 a 38 dias, com necessidades de 425 a $475 \mathrm{UC}$, tendo um crescimento ótimo em temperaturas diurnas de $30^{\circ} \mathrm{C}$ e noturnas de $22{ }^{\circ} \mathrm{C}$ (Rosolem, 2001; Beltrão \& Souza, 2001). Assim, pode-se observar que as condições climáticas do período (figuras 1 a 7) interferiram no surgimento do primeiro botão floral, o qual ocorreu aos 41 dias após a emergência, com 356,7 UC.

Os demais estádios não sofreram influências negativas das condições climáticas e tiveram o desenvolvimento semelhantes aos observados por Oosterhuis, (1999) em Arkansas, ou seja, 47-60 dias da emergência a primeira flor, 125-161 dias da emergência ao primeiro capulho e 120-180 dias da emergência a colheita. Porém, a necessidade de unidades de calor da semeadura à colheita para as cultivares estudadas, foi inferior à observada pelo autor (2.600 UC), em cultivares americanas. Entretanto, Rosolem (2001), em trabalho realizado em Rondonópolis, observou uma menor soma calórica, aproximadamente 1.645 UC, para as cultivares ITA 90 e Antares, da semeadura à colheita.

As condições ambientais durante a condução do experimento não influenciaram nas características intrínsecas das cultivares quanto ao ciclo de crescimento. A cultivar CD 401 de ciclo precoce completou o ciclo em 132 dias, ou seja, duas semanas antes da IAC 23 de ciclo longo, e cerca de uma semana antes que a cultivar DeltaOpal de ciclo médio, confirmando portanto a escolha prévia das cultivares como representativas dos grupos das cultivares disponíveis na cultura algodoeira atualmente no Brasil. 


\subsection{Produção de algodão em caroço e precocidade de colheita}

\subsubsection{Produção de Algodão em Caroço}

A análise de variância (Tabela 5) dos dados obtidos para produção de algodão em caroço, revelou valores de $\mathrm{F}$ significativos a $5 \%$ de probabilidade apenas para as interações espaçamento x cultivar e cultivar x regulador. As médias de produção e das interações duplas estão representadas na tabela 6 e 7, respectivamente.

Tabela 5. Quadrado médio (QM), F da análise de variância (F) e coeficiente de variação dos resíduos $(\mathrm{CV})$ referentes a produção e precocidade para espaçamentos $(\mathrm{E})$, cultivares $(\mathrm{V})$, regulador $(\mathrm{R})$ e suas interações (média de 4 repetições). Piracicaba, SP.

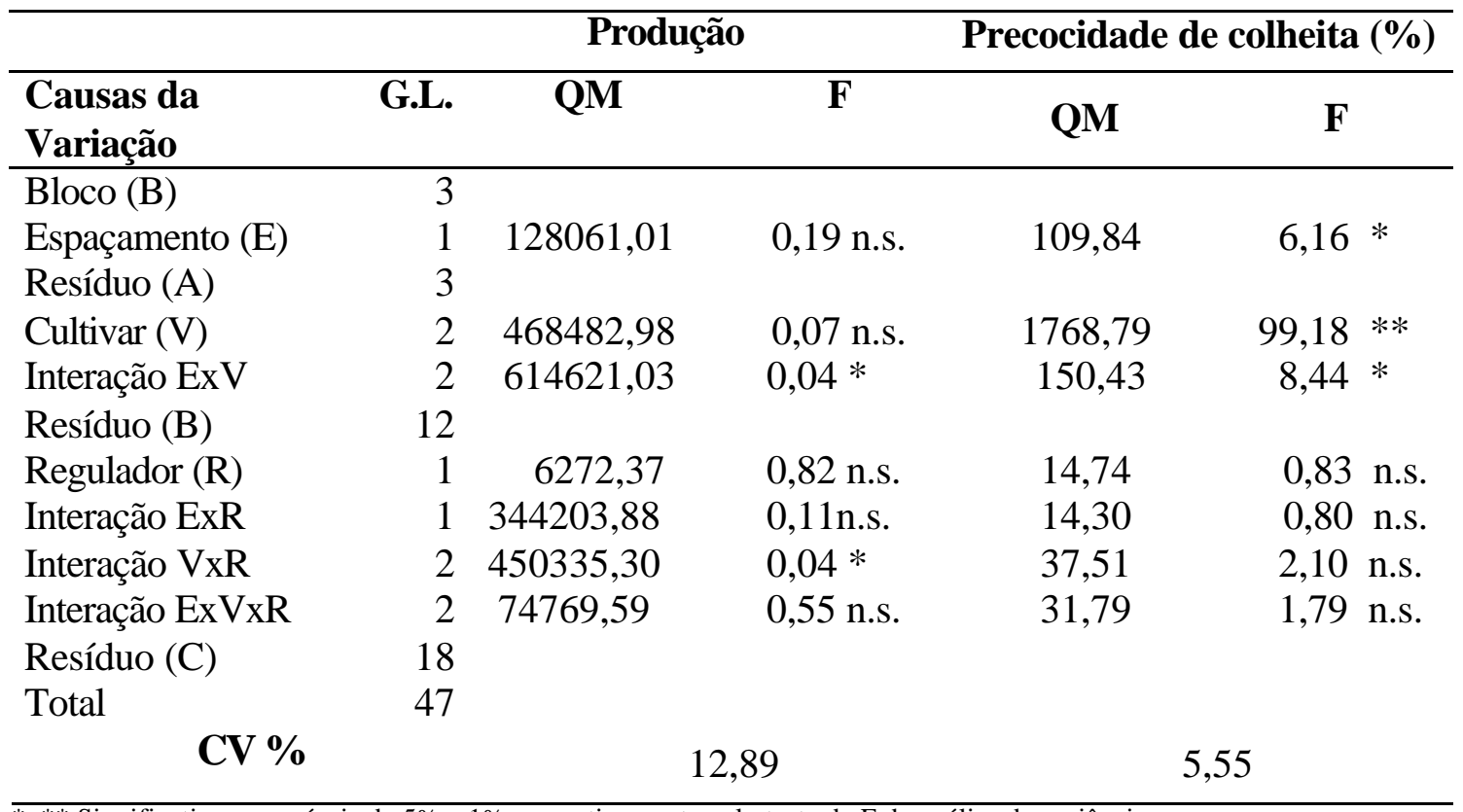

*,** Significativos aos níveis de 5\% e 1\% respectivamente pelo teste de $\mathrm{F}$ da análise da variância. 
Como se observa na tabela 5 e 6 não houve efeito isolado das variações dos espaçamentos e de cultivares na produção de algodão em caroço. Estes resultados assemelham-se aos de Belletini (1988) e Souza (1996), e pode ser justificado, concordando com os autores, pela capacidade de adaptação que a planta do algodoeiro possui, quando submetida a diferentes populações de plantas por área, independente das cultivares utilizadas. Ainda, constatou-se que não houve efeito isolado significativo da aplicação do regulador de crescimento sobre a produção de algodão em caroço (Tabela 6). Resultados semelhantes foram observados por Stuart et al. (1984), Laca-Buendia (1989) e Athayde \& Lamas (1999).

Tabela 6. Produção de algodão em caroço $\left(\mathrm{kg}^{-h a^{-1}}\right)$ e Precocidade de colheita (\%). Piracicaba, SP.

\begin{tabular}{|c|c|c|}
\hline Tratamentos & Produção kg.ha $^{-1}$ & Precocidade de colheita $(\%)$ \\
\hline$\overline{E_{1}(0,76 m)}$ & 2743,83 a & $74,53 \mathrm{~b}$ \\
\hline$E_{2}(1,01 m)$ & 2640,53 a & 77,55 a \\
\hline $\mathbf{F}$ & 2,92 n.s. & $6,16 *$ \\
\hline C.V. $(\%)$ & 12,89 & 5,55 \\
\hline DMS (5\%) & 192,55 & 2,61 \\
\hline $\mathrm{V}_{1}(\mathrm{IAC} 23)$ & $2814,00 \mathrm{a}$ & $70,65 \mathrm{~b}$ \\
\hline $\mathrm{V}_{2}$ (DeltaOpal) & 2496,50 a & $69,32 \mathrm{~b}$ \\
\hline$V_{3}(C D 401)$ & $2766,00 \mathrm{a}$ & 88,16 a \\
\hline $\mathbf{F}$ & 3,30 n.s. & $99,18 * *$ \\
\hline C.V. $(\%)$ & 12,89 & 5,55 \\
\hline DMS (5\%) & 355,56 & 11,76 \\
\hline $\mathrm{R}_{1}$ (S/ regulador) & $2680,70 \mathrm{a}$ & $75,60 \mathrm{a}$ \\
\hline $\mathbf{R}_{2}$ (c/ regulador $)$ & $2703,60 \mathrm{a}$ & 75,49 a \\
\hline $\mathbf{F}$ & 0,05 n.s. & 0,83 n.s. \\
\hline C.V. $(\%)$ & 12,89 & 5,55 \\
\hline DMS $(5 \%)$ & 210,46 & 2,56 \\
\hline
\end{tabular}


Quando analisa-se a interação das cultivares com os espaçamentos (Tabela 7), nota-se, no espaçamento mais adensado, maior produção da cultivar DeltaOpal e IAC 23, diferindo, a DeltaOpal, estatisticamente da cultivar CD 401, nesta condição. Possivelmente a cultivar DeltaOpal apresenta menor competitividade intraespecífica que as demais cultivares nas condições estudadas. Por outro lado, no espaçamento mais amplo $(1,01 \mathrm{~m})$ não foram encontradas diferenças estatísticas significativas entre as cultivares onde a competição entre plantas é menor, favorecendo igualmente o crescimento e desenvolvimento destas. Porém não houve variação na produção das cultivares nos espaçamentos avaliados, ou seja, a produção das cultivares foi semelhante na média dos nos espaçamentos de 0,76 e 1,01 m. Resultados estes que concordam com Carvalho et al. (2001a) os quais, estudando a cultivar IAC 23 em diferentes espaçamentos $(0,76$ e $0,95 \mathrm{~m})$ não observaram diferenças significativas na produção final.

Na avaliação da interação das cultivares com o regulador de crescimento (Tabela 7), nota-se que, no tratamento sem regulador de crescimento, a cultivar DeltaOpal foi menos produtiva que as cultivares IAC 23 e CD 401, no entanto, não diferindo estatisticamente da cultivar CD 401. Com a aplicação do regulador de crescimento as cultivares CD 401 e IAC 23 também foram mais produtivas que a DeltaOpal, porém sem diferir significativamente da cultivar IAC 23.

Tais comportamentos podem ser explicados, possivelmente, pela capacidade produtiva intrínseca de cada cultivar. Ou seja, nas condições em que o experimento foi conduzido, as cultivares IAC 23 e a CD 401, possivelmente, favorecidas pelas condições ambientais, puderam expressar favoravelmente o potencial produtivo, apresentando as maiores média de produção. 
Tabela 7. Produção: Interação cultivar $\mathrm{x}$ espaçamento e cultivar $\mathrm{x}$ regulador de crescimento. Piracicaba, SP.

\begin{tabular}{|c|c|c|c|c|c|}
\hline \multirow{3}{*}{1} & \multirow{3}{*}{$\begin{array}{l}\text { Cultivare } \\
\text { S }\end{array}$} & \multicolumn{4}{|c|}{ Produção } \\
\hline & & \multicolumn{2}{|c|}{ Espaçamento } & \multicolumn{2}{|c|}{ Regulador } \\
\hline & & $E_{1}(0,76 m)$ & $E_{2}(1,01 \mathrm{~m})$ & s/reg. & c/ reg. \\
\hline 2 & IAC 23 & 2706,15 a $A B$ & 2488,84 a A & 2984,09 a $\mathrm{A}$ & 2643,83 a $\mathrm{AB}$ \\
\hline & eltaOpal & 3036,50 a A & 2921,70 a A & 2452,83 a B & 2540,25 a B \\
\hline & D 401 & 2504,23 a B & 2495,57 a A & 2605,33 a $A B$ & 2926,75 a A \\
\hline \multicolumn{2}{|c|}{$\mathbf{F}$} & \multicolumn{2}{|c|}{$4,32 * *$} & \multicolumn{2}{|c|}{$3,74 * *$} \\
\hline \multicolumn{2}{|c|}{ C.V. (\%) } & \multicolumn{2}{|c|}{12,89} & \multicolumn{2}{|c|}{12,89} \\
\hline \multicolumn{2}{|c|}{ DMS (\%) } & \multicolumn{2}{|c|}{410,50} & \multicolumn{2}{|c|}{364,38} \\
\hline
\end{tabular}

*, ** Significativos aos níveis de $5 \%$ e $1 \%$ respectivamente pelo teste de $\mathrm{F}$ da análise da variância.

Médias seguidas da mesma letra maiúscula, na vertical, não diferem entre si pelo teste de Tukey, ao nível de 5\% de probabilidade. Médias seguidas da mesma letra minúscula, na horizontal, não diferem entre si pelo teste de Tukey, ao nível de 5\% de probabilidade.

\subsubsection{Precocidade de colheita}

De acordo com a tabela 5 de análise de variância, verifica-se efeitos isolados dos espaçamentos e das cultivares bem como, interação significativa entre espaçamento $\mathrm{x}$ cultivares, para a característica precocidade de colheita. Na tabela 6, podemos notar que, o espaçamento de 1,01 m favoreceu, de certa forma, a precocidade de colheita, resultados que contrariam os observados por Fower \& Ray (1977), no Texas, onde as cultivares estudadas não apresentaram diferenças na precocidade com relação aos espaçamentos adotados. Pode-se notar ainda, diferenças estatísticas entre as cultivares no que diz respeito à precocidade de colheita, sendo que a cultivar CD 401 apresentou maior média. Entre as cultivares DeltaOpal e IAC 23 não foram observadas diferenças significativas para esta característica.

A aplicação de regulador de crescimento não influenciou na precocidade de colheita das cultivares avaliadas (Tabela 6). Banci (1992) e Cia et al. (1996) 
obtiveram resultados contrários, observando aumento da precocidade com a aplicação do regulador de crescimento.

Quanto ao efeitos significativo para a interação cultivares $\mathrm{x}$ espaçamentos, observa-se na tabela 8 que a colheita na cultivar DeltaOpal, no espaçamento de $1,01 \mathrm{~m}$, foi mais precoce que no espaçamento mais adensado. Do mesmo modo, apesar de não significativo, a cultivar IAC 23 apresenta comportamento semelhante. Ao contrario, a cultivar CD 401, embora não apresente diferença significativa entre os espaçamentos, tem comportamento em direção contraria das demais cultivares. Pela análise geral dos dados, não se pode concluir que as diferentes arquiteturas das plantas tenha grande influência na precocidade de colheita. Neste caso, o habito de crescimento do algodoeiro pode explicar as diferenças entre as cultivares. Assim, no caso da DeltaOpal, diferindo das demais, pode-se atribuir a uma característica intrínseca da cultivar, favorecida pela maior penetração de luz e perda de umidade no dossel, favorecendo a abertura das maçãs.

Tabela 8. Precocidade de colheita: Interação cultivar x espaçamento. Piracicaba, SP.

3 Cultivares

\begin{tabular}{|c|c|c|}
\hline & $\mathrm{E}_{1}(0,76 \mathrm{~m})$ & $\mathrm{E}_{2}(1,01 \mathrm{~m})$ \\
\hline 4 IAC 23 & 68,96 a B & 72,34 a B \\
\hline DeltaOpal & 64,83 b B & 73,81 a B \\
\hline CD 401 & 89,80 a $\mathrm{A}$ & 86,52 a $A$ \\
\hline $\mathbf{F}$ & \multicolumn{2}{|c|}{$8,44 *$} \\
\hline C.V. (\%) & \multicolumn{2}{|c|}{5,55} \\
\hline DMS (\%) & \multicolumn{2}{|c|}{7,33} \\
\hline
\end{tabular}

*, ** Significativos aos níveis de 5\% e 1\% respectivamente pelo teste de $\mathrm{F}$ da análise da variância.

Médias seguidas da mesma letra maiúscula, na vertical, não diferem entre si pelo teste de Tukey, ao nível de $5 \%$ de probabilidade. Médias seguidas da mesma letra minúscula, na horizontal, não diferem entre si pelo teste de Tukey, ao nível de 5\% de probabilidade. 


\subsection{Caracteres agronômicos de campo}

\subsubsection{Altura de planta}

Na tabela 9 observamos o quadrado médio, $\mathrm{F}$ da análise de variância e o coeficiente de variação dos resíduos referentes a altura de plantas nos diferentes períodos de avaliação, para espaçamentos, cultivares, regulador de crescimento e suas interações. Verifica-se nesta tabela o efeito significativo da interação tripla apenas na avaliação aos 130 DAE, não observando, porém, diferenças nos demais períodos de avaliação.

Analisando-se a tabela 9, verifica-se que a altura das plantas não sofreu efeito isolado dos espaçamentos entre fileiras em nenhum dos período avaliados. Resultados semelhantes foram observados por Bellettine (1988), em estudo realizado no norte do Paraná, com a cultivar IAC 20, em espaçamento de 0,80; 0,90; e 1,00 m. O que significa que a pressão populacional exercida nos espaçamentos utilizados interferiu no porte das plantas de forma similar, independente da cultivar utilizada, possivelmente a mesma competição entre plantas, principalmente por luz, água e nutrientes, em ambos os espaçamentos. Lamas et al. (1989) em Minas Gerais, estudando a cultivar IAC 20 e Jost e Cothren (2001) nos Estados Unidos, estudando a cultivar 'Stoneville BXN-47', em espaçamentos que variaram de 0,19 a 1,01 m, não encontraram diferenças significativas para os espaçamentos superiores a 0,60 m, resultado que vem corroborar aos observados neste estudo. Os resultados de Nobrega et al. (1993), Souza (1996), e Carvalho et al. (2001b) estudando três cultivares (IAC 19; IAC 20; e CNPA Precoce 1), também, indicaram que não houve efeito do espaçamento na altura das plantas. 
Tabela 9. Quadrado médio (QM), F da análise de variância (F) e coeficiente de variação dos resíduos (CV) referentes a altura de plantas para espaçamentos (E), cultivares (V), regulador (R) e suas interações (média de 4 repetições). Piracicaba, SP.

\begin{tabular}{|c|c|c|c|c|c|c|c|c|c|}
\hline \multirow[b]{3}{*}{$\begin{array}{l}\text { Causas da } \\
\text { Variação }\end{array}$} & \multirow[b]{3}{*}{ G L } & \multicolumn{8}{|c|}{ Altura (cm) } \\
\hline & & \multicolumn{2}{|c|}{45 DAE } & \multicolumn{2}{|c|}{75 DAE } & \multicolumn{2}{|c|}{90 DAE } & \multicolumn{2}{|c|}{130 DAE } \\
\hline & & QM & $\mathbf{F}$ & QM & $\mathbf{F}$ & QM & $\mathbf{F}$ & QM & $\mathbf{F}$ \\
\hline Bloco (B) & 3 & & & & & & & & \\
\hline Espaç. (E) & 1 & 18,25 & 0,28 n.s. & 25,18 & 0,12 n.s. & 13,13 & 0,10 n.s. & 82,69 & 1,19 n.s. \\
\hline Resíduo (A) & 3 & & & & & & & & \\
\hline Cultivar (V) & 2 & 221,77 & $6,46 * *$ & 69,19 & 1,36 n.s. & 1056,84 & $8,20 * *$ & 2966,09 & $15,28 * *$ \\
\hline Interação ExV & 2 & 156,02 & $4,55 *$ & 197,07 & $3,87 * *$ & 69,58 & 0,54 n.s. & 24,99 & 0,13 n.s. \\
\hline Resíduo (B) & 12 & & & & & & & & \\
\hline Regulador (R) & 1 & 11,80 & 0,44 n.s. & 959,44 & $9,64 * *$ & 1741,22 & $24,23 * *$ & 4427,52 & $48,53 * *$ \\
\hline Interação ExR & 1 & 52,08 & 1,94 n.s. & 136,01 & 1,37 n.s. & 54,83 & 0,76 n.s. & 91,85 & 1,01 n.s. \\
\hline Interação VxR & 2 & 16,69 & 0,62 n.s. & 773,42 & 7,77 n.s. & 645,92 & $8,99 * *$ & 1250,45 & $13,71 * *$ \\
\hline Inter. ExVxR & 2 & 34,36 & 1,28 n.s. & 266,33 & 2,68 n.s. & 184,28 & 2,56 n.s. & 473,41 & $5,19 *$ \\
\hline Resíduo (C) & 18 & & & & & & & & \\
\hline Total & 47 & & & & & & & & \\
\hline C.V.\% & & & 35 & & & & 05 & & 19 \\
\hline
\end{tabular}


Cada cultivar estudada apresenta características genéticas e morfológicas próprias e como era esperado, as médias de altura de plantas apresentaram diferenças significativas entre as cultivares (Tabela 10). A cultivar CD 401, de crescimento determinado e de plantas mais compactas, terminou o ciclo com a menor média $(118,26 \mathrm{~cm})$. A cultivar IAC 23 de desenvolvimento intenso, encerrou o ciclo com a maior média $(145,18 \mathrm{~cm})$, porém não diferindo estatisticamente da cultivar DeltaOpal, na última avaliação $(132,25 \mathrm{~cm})$.

Com relação ao efeito do regulador de crescimento sobre a altura das plantas (Tabela 10), pode-se observar que nos tratamentos com regulador de crescimento como era esperado, as plantas apresentaram porte menor nas avaliações feitas aos 75, 90 e 130 DAE, fato que confirma a tendência do regulador em reduzir o porte das plantas. Resultados semelhantes, com redução na altura de plantas com aplicação de cloreto de mepiquat, foram verificados por vários autores. Essa redução na altura das plantas de algodoeiro é favorável, principalmente em condições que favoreçam crescimento vegetativo excessivo.

Stuart et al. (1984), Barbosa \& Castro (1984), Laca-Buendia (1989), Reddy et al. (1990), Banci (1992), York (1993), Cia et al. (1996), Athayde \& Lamas (1999), Soares (1999) e Lamas et al. (2000) também observaram que a aplicação de cloreto de mepiquat provoca redução na altura das plantas, confirmando os resultados obtidos no presente trabalho.

De acordo com Mohamed et al. (1982) diferentes genótipos podem responder de maneira diferente aos espaçamentos entre fileiras. De fato, na interação do espaçamento com as cultivares (Tabela 11) foram observadas diferenças significativas no período de crescimento e desenvolvimento da cultura, aos 45 e 75 DAE. Tal ocorrência pode ser justificada pelo fato de que aos 45 DAE, ainda não ocorreu neste período, o fechamento do dossel das plantas. No caso particular da cultivar CD 401, que é uma cultivar precoce, o espaçamento interferiu no crescimento logo nos primeiros dias de desenvolvimento, sendo favorecida pelo espaçamento de $0,76 \mathrm{~m}$, que pode ter proporcionado melhores condições ambientais neste período onde a competição entre as plantas ainda não é 
tão pronunciado. Assim como, as cultivares IAC 23 e DeltaOpal que aos 75 DAE também apresentaram plantas de maior porte no menor espaçamento. Em contra partida a cultivar CD 401, apresentou plantas de menor porte aos 75 DAE no espaçamento de $0,76 \mathrm{~cm}$, provavelmente pelo aumento de competição das plantas no menor espaçamento. Após este período, nas demais avaliações, 90 e 130 DAE, as diferenças deixaram de existir, devido ao aumento da competição das plantas no espaçamento menor.

Tabela 10. Caracteres agronômicos de campo: altura de plantas (cm). Piracicaba, SP.

\begin{tabular}{|c|c|c|c|c|}
\hline \multirow[b]{2}{*}{ Tratamentos } & \multicolumn{4}{|c|}{ Altura $(\mathrm{cm})$} \\
\hline & 45 DAE & 75 DAE & 90 DAE & 130 DAE \\
\hline$E_{1}(0,76 m)$ & $46,27 \mathrm{a}$ & $97,65 \mathrm{a}$ & $119,72 \mathrm{a}$ & 131,59 a \\
\hline $\mathrm{E}_{2}(1,01 \mathrm{~m})$ & $45,04 \mathrm{a}$ & 99,12 a & $120,77 \mathrm{a}$ & $134,21 \mathrm{a}$ \\
\hline $\mathbf{F}$ & 0,28 n.s. & 0,12 n.s. & 0,10 n.s. & 1,19 n.s. \\
\hline C.V. (\%) & 11,35 & 10,13 & 7,04 & 7,18 \\
\hline DMS (5\%) & 7,37 & 13,56 & 10,64 & 7,65 \\
\hline$V_{1}($ IAC 23) & $48,63 \mathrm{ab}$ & 99,23 a & 127,78 a & 145,18 a \\
\hline$V_{2}$ (DeltaOpal) & $41,48 \quad b$ & 99,91 a & $121,30 \mathrm{ab}$ & $135,25 \mathrm{a}$ \\
\hline$V_{3}(C D 401)$ & 43,63 a & $99,01 \mathrm{a}$ & $111,63 \mathrm{~b}$ & $118,26 \mathrm{~b}$ \\
\hline $\mathbf{F}$ & $6,46 * *$ & 1,36 n.s. & $8,23 * *$ & $15,28 * *$ \\
\hline C.V. $(\%)$ & 11,35 & 10,13 & 7,04 & 7,18 \\
\hline DMS (5\%) & 5,52 & 6,72 & 10,70 & 13,14 \\
\hline $\mathbf{R}_{1}$ (s/ regulador) & $46,15 \mathrm{a}$ & $102,86 \mathrm{a}$ & $126,27 \mathrm{a}$ & $142,50 \mathrm{a}$ \\
\hline $\mathbf{R}_{2}$ (c/ regulador $)$ & 45,16 a & $93,92 \mathrm{~b}$ & $114,22 \mathrm{~b}$ & $123,29 \mathrm{~b}$ \\
\hline $\mathbf{F}$ & 0,44 n.s. & $9,64 * *$ & $24,23 * *$ & $48,53 * *$ \\
\hline C.V. (\%) & 11,35 & 10,13 & 7,04 & 7,18 \\
\hline DMS (5\%) & 3,14 & 6,04 & 5,14 & 5,79 \\
\hline
\end{tabular}


Tabela 11. Caracteres agronômicos de campo: Interação cultivar x espaçamento para a altura de plantas (cm). Piracicaba, SP.

\begin{tabular}{|c|c|c|c|c|}
\hline \multirow{3}{*}{5 Cultivares } & \multicolumn{4}{|c|}{ Altura (cm) } \\
\hline & \multicolumn{2}{|c|}{$45 \mathrm{DAE}$} & \multicolumn{2}{|c|}{$75 \mathrm{DAE}$} \\
\hline & $E_{1}(0,76)$ & $E_{2}(1,01)$ & $E_{1}(0,76)$ & $E_{2}(1,01)$ \\
\hline $\begin{array}{ll}6 & \text { IAC } 23\end{array}$ & 45,91 a $\mathrm{AB}$ & 47,81 a A & 110,37 a $\mathrm{A}$ & 88,09 b B \\
\hline DeltaOpal & 40,07 a $B$ & 42,90 a $\mathrm{A}$ & 104,91 a $\mathrm{A}$ & $94,91 \mathrm{~b} \mathrm{~A}$ \\
\hline CD 401 & 52,85 a $\mathrm{A}$ & 44,42 b A & 93,28 a B & 98,75 a $\mathrm{A}$ \\
\hline $\mathbf{F}$ & \multicolumn{2}{|c|}{$4,55 * *$} & \multicolumn{2}{|c|}{$3,87 * *$} \\
\hline C.V. $(\%)$ & \multicolumn{2}{|c|}{11,35} & \multicolumn{2}{|c|}{10,19} \\
\hline DMS & \multicolumn{2}{|c|}{6,37} & \multicolumn{2}{|c|}{7,76} \\
\hline
\end{tabular}

*, ** Significativos aos níveis de 5\% e 1\% respectivamente pelo teste de $\mathrm{F}$ da análise da variância.

Médias seguidas da mesma letra maiúscula, na vertical, não diferem entre si pelo teste de Tukey, ao nível de 5\% de probabilidade.

Médias seguidas da mesma letra minúscula, na horizontal, não diferem entre si pelo teste de Tukey, ao nível de 5\% de probabilidade.

$\mathrm{Na}$ interação cultivar $\mathrm{x}$ regulador de crescimento nota-se um efeito mais pronunciado do regulador de crescimento nas cultivares de crescimento mais intenso, IAC 23 e DeltaOpal, que diferiram estatisticamente da cultivar CD 401 na altura final (Tabela 12). De fato, Lamas (2001) evidência o efeito mais positivo do regulador de crescimento em cultivares de porte e ciclo mais longo.

Em relação à resposta diferencial de cultivares ao regulador de crescimento, York (1983) trabalhando com diferentes cultivares, na Carolina do Norte, observou respostas diferentes ao cloreto de mepiquat em quatorze cultivares. Do mesmo modo, neste estudo verificou-se que a aplicação do regulador de crescimento reduziu de 11 a $26 \%$ a altura final das plantas (Tabela 12). 
Tabela 12. Caracteres agronômicos de campo: Interação cultivar x regulador de crescimento para a altura de plantas (cm). Piracicaba, SP.

\begin{tabular}{|c|c|c|c|c|c|c|c|}
\hline \multirow{3}{*}{7} & \multirow{3}{*}{$\begin{array}{l}\text { Cultivar } \\
\text { es }\end{array}$} & \multicolumn{6}{|c|}{ Altura $(\mathrm{cm})$} \\
\hline & & \multicolumn{2}{|c|}{75 DAE } & \multicolumn{2}{|c|}{90 DAE } & \multicolumn{2}{|c|}{130 DAE } \\
\hline & & s/ reg. & c/ reg. & s/reg. & c/ reg. & s/ reg. & c/ reg \\
\hline 8 & IAC 23 & 110,38 a $\mathrm{A}$ & 88,09 b A & 140,45 a $\mathrm{A}$ & $115,12 \mathrm{~b} \mathrm{~A}$ & 164,17 a $\mathrm{A}$ & $126,21 \mathrm{~b} \mathrm{~A}$ \\
\hline & eltaOpal & $104,91 \mathrm{a} A B$ & 94,91 a $\mathrm{A}$ & 126,71 a B & 115,90 a A & 143,68 a B & $126,82 \mathrm{~b} \mathrm{~A}$ \\
\hline & D 401 & 93,29 a B & 98,75 a $\mathrm{A}$ & 111,64 a C & 111,64 a A & 119,68 a C & 116,85 a $\mathrm{A}$ \\
\hline \multicolumn{2}{|c|}{$\mathbf{F}$} & \multicolumn{2}{|c|}{$7,77 * *$} & \multicolumn{2}{|c|}{$8,99 * *$} & \multicolumn{2}{|c|}{$13,71 * *$} \\
\hline \multicolumn{2}{|c|}{ C.V. $(\%)$} & \multicolumn{2}{|c|}{10,13} & \multicolumn{2}{|c|}{7,05} & \multicolumn{2}{|c|}{7,18} \\
\hline \multicolumn{2}{|c|}{ DMS (\%) } & \multicolumn{2}{|c|}{10,47} & \multicolumn{2}{|c|}{8,90} & \multicolumn{2}{|c|}{10,03} \\
\hline
\end{tabular}

*, ** Significativos aos níveis de 5 e $1 \%$ respectivamente pelo teste de $\mathrm{F}$ da análise da variância.

Médias seguidas da mesma letra maiúscula, na vertical, não diferem entre si pelo teste de Tukey, ao nível de $5 \%$ de probabilidade.

Médias seguidas da mesma letra minúscula, na horizontal, não diferem entre si pelo teste de Tukey, ao nível de 5\% de probabilidade.

Quando avalia-se a interação das três variáveis, cultivar x regulador $\mathrm{x}$ espaçamento (Tabela 13) percebe-se claramente as diferenças genéticas/morfológicas de cada cultivar com relação ao manejo utilizado. A cultivar CD 401, por possuir uma arquitetura de planta mais compacta e ter desenvolvimento mais determinado, não sofreu influência do espaçamento e do regulador de crescimento, no que diz respeito a altura final das plantas. A cultivar IAC 23, de desenvolvimento vigoroso e ciclo mais longo, respondeu ao regulador de crescimento apresentando plantas de porte menor nos tratamentos com regulador em ambos os espaçamentos. A cultivar DeltaOpal sofreu influência do regulador de crescimento apenas no espaçamento mais amplo $(1,01 \mathrm{~m})$. Tais resultados evidenciam a necessidade de ajuste de doses de regulador de crescimento em função da cultivar e do espaçamento adotado, quanto à altura final das plantas. 
Tabela 13. Caracteres agronômicos de campo: Interação espaçamento $\mathrm{x}$ cultivar $\mathrm{x}$ regulador de crescimento para a altura de plantas $(\mathrm{cm})$. Piracicaba, SP.

\begin{tabular}{|c|c|c|c|c|}
\hline \multirow[b]{2}{*}{ Tratamentos } & \multicolumn{4}{|c|}{ Altura (cm) } \\
\hline & 45 DAE & 75 DAE & 90 DAE & 130 DAE \\
\hline IAC 23 /Esp. 0,76m/Sem Reg. & $45,54 \mathrm{a}$ & $109,58 \mathrm{a}$ & $140,08 \mathrm{a}$ & $166,25 \mathrm{a}$ \\
\hline IAC 23 /Esp. 0,76m/Com Reg. & $46,25 \mathrm{a}$ & 83,25 a & $111,67 \mathrm{a}$ & $119,43 \mathrm{c}$ \\
\hline IAC 23 /Esp. 1,01m/Sem Reg. & $48,33 \mathrm{a}$ & $111,17 \mathrm{a}$ & $140,83 \mathrm{a}$ & $162,08 \mathrm{a}$ \\
\hline IAC 23 /Esp. 1,01m/Com Reg. & 47,29 a & 92,92 a & $118,58 \mathrm{a}$ & $133,00 \quad b$ \\
\hline DeltaOpal/Esp. 0,76m/Sem Reg. & 37,46 a & $96,17 \mathrm{a}$ & $120,25 \mathrm{a}$ & 135,68 \\
\hline DeltaOpal /Esp. 0,76m/Com Reg. & 42,71 a & 98,25 a & $119,25 \mathrm{a}$ & 131,50 \\
\hline DeltaOpal /Esp. 1,01m/Sem Reg. & $45,71 \mathrm{a}$ & $113,67 \mathrm{a}$ & 133,17 a & 151,68 \\
\hline DeltaOpal /Esp. 1,01m/Com Reg. & 40,08 a & 91,58 a & $112,50 \mathrm{a}$ & $122,15 \quad \mathrm{c}$ \\
\hline CD 401/Esp. 0,76m/Sem Reg. & 51,21 a & 95,58 a & 113,67 a & 117,50 \\
\hline CD 401/Esp. 0,76m/Com Reg. & 54,50 a & $103,08 \mathrm{a}$ & 113,33 a & $119,18 \quad \mathrm{c}$ \\
\hline CD 401/Esp. 1,01m/Sem Reg. & 42,71 a & $91,00 \mathrm{a}$ & 109,58 a & 121,85 \\
\hline CD 401/Esp. 1,01m/Com Reg. & 46,13 a & 94,42 a & $109,92 \mathrm{a}$ & $114,53 \mathrm{c}$ \\
\hline $\mathbf{F}$ & $1,28 \mathrm{n} . \mathrm{s}$ & 2,68 n.s. & $2,56 \mathrm{n} . \mathrm{s}$ & $5,19 * *$ \\
\hline C.V. $(\%)$ & 11,35 & 10,14 & 7,05 & 7,18 \\
\hline $\operatorname{DMS}(5 \%)$ & & & & 12,37 \\
\hline
\end{tabular}

Médias seguidas da mesma letra não diferem entre si pelo teste de Tukey, ao nível de 5\% de probabilidade.

\subsubsection{Diâmetro do caule}

As análises de variância dos resultados referentes ao diâmetro de caule e as médias obtidas na análise de variância para esta característica, encontram-se nas tabela 14 e 15, respectivamente. Pode-se observar a ocorrência de efeito isolados e interação tripla entre os tratamentos. 
O diâmetro do caule foi menor quando se reduziu o espaçamento entre fileiras (Tabelas 15). A redução do diâmetro de caule, com a redução do espaçamento entre fileiras, pode ser explicado pela maior competição verificada nessas condições. Esse resultado está de acordo com Fower \& Ray (1977), Lamas (1988), Banci (1992) e Souza (1996). No entanto, Nobrega et al. (1993) não encontraram variações no diâmetro de caule em diferentes arranjos de plantas, contrariando os resultados anteriores. Isto pode ter ocorrido possivelmente pelo baixo estande estudado (50.000 plantas por hectare).

Quanto aos efeitos do cloreto de mepiquat (Tabela 15), observou-se redução do diâmetro do caule quando este produto foi aplicado, o resultado esta de acordo com Laca-Buendia (1989), Barbosa (1983) e Banci (1992).

A redução do diâmetro de caule foi mais expressiva na cultivar DeltaOpal, sendo influenciada pelo espaçamento de $0,76 \mathrm{~m}$ e pela aplicação de regulador de crescimento no espaçamento de 1,01 m. Na cultivar IAC 23 a redução do diâmetro de caule foi significativa no espaçamento $0,76 \mathrm{~m}$ apenas com regulador de crescimento. Esta cultivar, por apresentar um crescimento mais intenso no maior espaçamento, não apresentou redução no diâmetro do caule em presença do regulador de crescimento. Contrariamente, a cultivar CD 401, por apresentar plantas mais compactas, não sofreu influência dos tratamento adotados (Tabela 16). Este caráter é particularmente importante nas maiores densidades de plantas por área, aonde é possível ocorrer o acamamento das plantas devido o deslocamento da produção para os ponteiros das plantas associado à redução do diâmetro do caule. 
Tabela 14. Quadrado médio $(\mathrm{QM}), \mathrm{F}$ da análise de variância $(\mathrm{F})$ e coeficiente de variação dos resíduos (CV) referentes aos parâmetros avaliados das características de campo para espaçamentos (E), cultivares (V), regulador (R) e suas interações (média de 4 repetições). Piracicaba, SP.

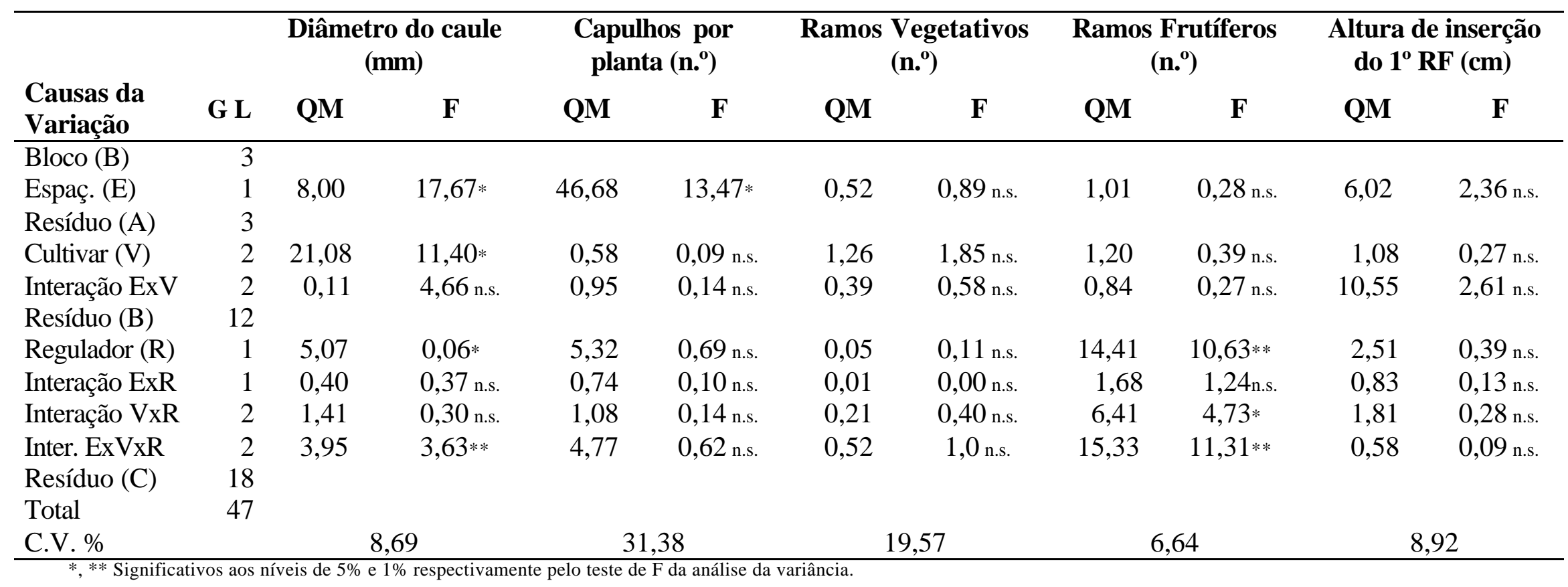


Tabela 15. Caracteres agronômicos de campo: diâmetro de caule, número de maças por planta, número de ramos vegetativos e frutíferos e altura de inserção do primeiro ramo frutífero. Piracicaba, SP.

\begin{tabular}{|c|c|c|c|c|c|}
\hline Tratamentos & $\begin{array}{c}\text { Diâmetro do caule } \\
\text { (mm) }\end{array}$ & $\begin{array}{l}\text { Capulhos por } \\
\text { planta }\left(\text { n. }^{\circ}\right)\end{array}$ & $\begin{array}{c}\text { Ramos Vegetativos } \\
\left.\text { (n. }{ }^{\mathbf{o}}\right)\end{array}$ & $\begin{array}{c}\text { Ramos Frutíferos } \\
\left(\text { (n. }^{\circ}\right)\end{array}$ & $\begin{array}{l}\text { Altura de inserção } \\
\text { do } 1^{\circ} \mathrm{RF}(\mathrm{cm})\end{array}$ \\
\hline$\overline{E_{1}(0,76 m)}$ & $11,58 \mathrm{~b}$ & $7,84 \mathrm{~b}$ & $3,57 \mathrm{a}$ & 17,38 a & 28,13 a \\
\hline$E_{2}(1,01 m)$ & $12,40 \mathrm{a}$ & 9,81 a & 3,77 a & $17,68 \mathrm{a}$ & $28,84 \mathrm{a}$ \\
\hline $\mathbf{F}$ & $17,68 * *$ & $13,47 *$ & 0,89 n.s. & 0,28 n.s. & 3,36 n.s. \\
\hline C.V. (\%) & 8,69 & 31,38 & 19,56 & 6,63 & 8,93 \\
\hline DMS (5\%) & 0,62 & 1,17 & 0,70 & 1,75 & 1,46 \\
\hline$V_{1}($ IAC 23) & 13,25 a & 9,04 a & 3,39 a & 17,29 a & $28,33 \mathrm{a}$ \\
\hline$V_{2}$ (DeltaOpal) & $11,78 \quad b$ & 8,79 a & 3,95 a & 17,83 a & 28,35 a \\
\hline$V_{3}(C D 401)$ & $10,94 \mathrm{~b}$ & 8,66 a & $3,67 \mathrm{a}$ & $17,47 \mathrm{a}$ & 28,79 a \\
\hline $\mathbf{F}$ & $11,40 * *$ & 0,09 n.s. & 1,85 n.s. & 0,39 n.s. & 0,27 n.s. \\
\hline C.V. $(\%)$ & 8,69 & 31,38 & 19,56 & 6,63 & 8,93 \\
\hline DMS (5\%) & 1,30 & 2,43 & 0,77 & 1,65 & 1,89 \\
\hline $\mathbf{R}_{1}$ (s/ regulador $)$ & $12,31 \mathrm{a}$ & 9,16 a & 3,71 a & $18,08 \mathrm{a}$ & $28,72 \mathrm{a}$ \\
\hline $\mathbf{R}_{2}$ (c/ regulador $)$ & $11,66 \mathrm{~b}$ & $8,50 \mathrm{a}$ & 3,64 a & $16,98 \mathrm{~b}$ & 28,26 a \\
\hline $\mathbf{F}$ & $4,66 *$ & 0,69 n.s. & 0,11 n.s. & $10,63 * *$ & 0,39 n.s. \\
\hline C.V. (\%) & 8,69 & 31,38 & 19,56 & 6,63 & 8,93 \\
\hline DMS (5\%) & 0,63 & 1,68 & 0,43 & 0,71 & 1,54 \\
\hline
\end{tabular}

Médias seguidas da mesma letra na vertical não diferem entre si pelo teste de Tukey, ao nível de 5\% de probabilidade. 
Tabela 16. Caracteres agronômicos de campo: Interação espaçamento x cultivar x regulador de crescimento para o diâmetro do caule (mm). Piracicaba, SP.

\begin{tabular}{lc}
\hline Tratamentos & Diâmetro do caule (mm) \\
\hline IAC 23 /Esp. 0,76m/Sem Reg. & $13,93 \mathrm{a}$ \\
IAC 23 /Esp. 0,76m/Com Reg. & $11,88 \mathrm{~b}$ \\
IAC 23 /Esp. 1,01m/Sem Reg. & $13,83 \mathrm{a}$ \\
IAC 23 /Esp. 1,01m/Com Reg. & $13,38 \mathrm{a}$ \\
DeltaOpal/Esp. 0,76m/Sem Reg. & $11,00 \mathrm{~b}$ \\
DeltaOpal /Esp. 0,76m/Com Reg. & $11,55 \mathrm{~b}$ \\
DeltaOpal /Esp. 1,01m/Sem Reg. & $13,20 \mathrm{a}$ \\
DeltaOpal /Esp. 1,01m/Com Reg. & $11,38 \mathrm{~b}$ \\
CD 401/Esp. 0,76m/Sem Reg. & $10,53 \mathrm{~b}$ \\
CD 401/Esp. 0,76m/Com Reg. & $10,63 \mathrm{~b}$ \\
CD 401/Esp. 1,01m/Sem Reg. & $11,43 \mathrm{~b}$ \\
CD 401/Esp. 1,01m/Com Reg. & $11,20 \mathrm{~b}$ \\
F & $3,63 * *$ \\
C.V. (\%) & 8,69 \\
DMS (5\%) & 1,79 \\
\hline
\end{tabular}

Médias seguidas da mesma letra não diferem entre si pelo teste de Tukey, ao nível de 5\% de probabilidade.

\subsubsection{Número médio de capulhos por planta}

$\mathrm{Na}$ tabela 14, nota-se que, entre as cultivares, como efeito isolado, não houve diferenças no número de capulhos por plantas. Do mesmo modo a aplicação de regulador de crescimento também não afetou o número de capulhos por planta, esse resultado está de acordo com Barbosa (1983) e Banci (1992). 
Houve, porém, diferença significativa no número de capulhos por planta com as variações dos espaçamentos. Como pode-se notar na tabela 15, ocorreu um aumento do número de capulhos por planta no espaçamento mais largo, independente da arquitetura das plantas. $\mathrm{O}$ mesmo resultado foi observado por Lamas et al. (1989), Banci (1992), Souza (1996) e Carvalho et al. (2001). Tal fato pode ser explicado, considerando que, com a redução do espaçamento entre fileiras, a competição por luz, água e nutrientes aumenta entre as plantas e, com isso, há tendência de haver um menor número de frutos por planta, ocorrendo também com o adensamento da cultura, maior dificuldade de penetração de luz no dossel, associada à redução da aeração entre plantas, provocando desta forma a queda de frutos, reduzindo o seu número.

\subsubsection{Número de ramos vegetativos e frutíferos}

O número de ramos vegetativos basais não foi influenciado estatisticamente pelos espaçamentos, cultivares e regulador de crescimento, bem como não houve interações significativas entre os tratamento. Possivelmente este caráter possa ser alterado em densidades populacionais mais altas, como nos espaçamentos ultra adensados. Do mesmo modo o número de ramos frutíferos também não variou entre as cultivares e nem foi influenciado pelos espaçamentos, havendo efeito apenas do regulador de crescimento (Tabela 14 e15).

Fowler \& Ray (1977) no Texas, verificaram que altas populações de plantas diminuíram o número de ramos produtivos. Este fato foi confirmado por Lamas (1988) e Banci (1992), em Viçosa, contrariando os resultados deste trabalho onde os espaçamentos não influenciaram no número de ramos produtivos. Esta diferença pode ser em função das altas populações e pelo comportamento e arquitetura das cultivares utilizadas pelos autores mencionados. 
Barbosa (1983), estudando a ação do regulador de crescimento no algodoeiro, observou que a aplicação de cloreto de mepiquat tende a reduzir o número de ramos produtivos. De fato, verificando-se a tabela 15 podemos observar que o efeito do regulador de crescimento diminuiu, significativamente, o número de ramos frutíferos. Fator que pode estar na dependência da diminuição do porte da planta.

A interação do regulador de crescimento com as cultivares (Tabela 17), evidencia o menor número de ramos frutíferos na cultivar IAC 23. Fato que pode estar relacionado com a necessidade de maiores doses de regulador de crescimento para a redução da altura das plantas dessa cultivar de crescimento mais vigoroso. Para as cultivares DeltaOpal e CD 401 o efeito do regulador de crescimento, não foi significativo, não reduzindo o número de ramos frutíferos.

Tabela 17. Caracteres agronômicos de campo: Interação cultivar x regulador de crescimento para o número de ramos frutíferos. Piracicaba, SP.

\begin{tabular}{llc}
\hline Cultivares & Ramos Frutíferos (n. $\left.{ }^{\mathbf{0}}\right)$ \\
\hline 10 IAC 23 & c/ reg. & 16,04 b A \\
DeltaOpal & 18,54 a A & 17,46 a A \\
CD 401 & 18,21 a A & 17,45 a A \\
F & 17,49 a A & $4,73 * *$ \\
C.V. $(\%)$ & & 6,63 \\
DMS $(\mathbf{5 \% )}$ & & 1,22 \\
\hline
\end{tabular}

*, ** Significativos aos níveis de 5 e $1 \%$ respectivamente pelo teste de $\mathrm{F}$ da análise da variância.

Médias seguidas da mesma letra maiúscula, na vertical, não diferem entre si pelo teste de Tukey, ao nível de 5\% de probabilidade.

Médias seguidas da mesma letra minúscula , na horizontal, não diferem entre si pelo teste de Tukey, ao nível de 5\% de probabilidade. 


\subsubsection{Altura de inserção do primeiro ramo frutífero}

Nas tabelas 14 e15, verifica-se que a altura de inserção do primeiro ramo produtivo não sofreu efeito dos tratamentos avaliados. Resultados que concordam com os obtidos por Lamas (1988) que observou aumento da inserção do ramo frutífero da cultivar IAC 20, em espaçamentos menores, rão observando, porém, esta diferença quando avaliou-se os espaçamentos maiores de 0,60 m. Contrário a estes resultados, Yamaoka et al. (1982), estudando a densidade de plantas de algodoeiro sobre a inserção de ramos frutíferos, observaram que a altura da inserção dos primeiros ramos produtivos foi elevada pela redução do espaçamento. Porém, o aumento excessivo da população pode ter efeito negativo sobre a produção.

A altura de inserção do primeiro ramo frutífero foi semelhante para as cultivares estudadas, independente da arquitetura de cada cultivar. No que se refere ao efeito de regulador de crescimento, observa-se que, apesar deste ter reduzido a altura das plantas, não afetou, significativamente, a altura de inserção do primeiro ramo frutífero, o que proporciona em geral plantas mais compactas. Este dado é de relevante importância, uma vez que a altura de inserção do primeiro ramo frutífero interfere na colheita mecânica e na qualidade de fibra.

\subsubsection{Conformação da planta}

As análises de variância para comprimento do primeiro ramo frutífero, comprimento do ramo frutífero mediano e comprimento do último ramo frutífero estão representadas nas tabelas 18 e 19.

De modo geral a conformação das plantas foi influenciada pelos espaçamentos, observando-se redução no comprimento dos primeiros e nos últimos ramos frutíferos das plantas no menor espaçamento. $\mathrm{O}$ ramo frutífero mediano não sofreu efeito do espaçamento (Tabela 19). 
Apesar das cultivares estudadas apresentarem arquiteturas de plantas bem distintas, não foram observadas diferenças significativas no comprimento dos primeiros ramos frutíferos, assim como dos ramos medianos (Tabela 19). Os últimos ramos frutíferos das cultivares CD 401 e DeltaOpal, crescimento "determinado" e "semi-determinado", respectivamente, apresentaramse mais curtos do que os da cultivar IAC 23 que é uma cultivar de crescimento vigoroso e indeterminado.

O regulador de crescimento proporcionou efeitos significativos nos comprimentos de todos os ramos frutíferos avaliados (Tabela 19). Tal fato comprova a ação sistêmica do cloreto de mepiquat na redução do porte das plantas de algodão. Lamas et al. (2000) relatam que o cloreto de mepiquat inibe o crescimento dos ramos vegetativos basais em geral.

Na tabela 20, pela interação do regulador de crescimento com as cultivares, notamos que as cultivares IAC 23 e DeltaOpal sofreram efeitos do regulador de crescimento, apresentando os primeiros ramos mais curtos quando o cloreto de mepiquat foi aplicado. A cultivar CD 401 não foi influenciada pelo regulador de crescimento e apresentou ramos mais curtos que as demais cultivares. Para os demais ramos frutíferos, mediano e último, não foram observadas diferenças significativas. 
Tabela 18. Quadrado médio (QM), F da análise de variância (F) e coeficiente de variação dos resíduos (CV) referentes aos parâmetros avaliados das características de campo para espaçamentos (E), cultivares (V), regulador (R) e suas interações (média de 4 repetições). Piracicaba, SP.

\begin{tabular}{|c|c|c|c|c|c|c|c|}
\hline \multirow[b]{2}{*}{ Causas da Variação } & \multirow[b]{2}{*}{ G.L. } & \multicolumn{2}{|c|}{ Comp. do $1^{\circ}$ RF (cm) } & \multicolumn{2}{|c|}{$\begin{array}{l}\text { Comp. do RF médio } \\
\text { (cm) }\end{array}$} & \multicolumn{2}{|c|}{$\begin{array}{c}\text { Comp. do último RF } \\
\text { (cm) }\end{array}$} \\
\hline & & $\mathbf{Q M}$ & $\mathbf{F}$ & QM & $\mathbf{F}$ & $\mathbf{Q M}$ & $\mathbf{F}$ \\
\hline Bloco (B) & 3 & & & & & & \\
\hline Espaçamento (E) & 1 & 0,02 & $39,83 * *$ & 0,02 & 6,57 n.s. & 0,01 & $21,90 *$ \\
\hline Resíduo (A) & 3 & & & & & & \\
\hline Cultivar (V) & 2 & 0,01 & 1,64 n.s. & 0,01 & 1,84 n.s. & 0,01 & $27,69 * *$ \\
\hline Interação ExV & 2 & 0,00 & 0,00 n.s. & 0,00 & 0,01 n.s. & 0,01 & $2,53 \mathrm{n} . \mathrm{s}$ \\
\hline Resíduo (B) & 12 & & & & & & \\
\hline Regulador (R) & 1 & 0,05 & $18,47 * *$ & 0,05 & $18,05 * *$ & 0,01 & $11,59 * *$ \\
\hline Interação ExR & 1 & 0,01 & 0,87 n.s. & 0,01 & 2,34 n.s. & 0,00 & 0,11 n.s. \\
\hline Interação VxR & 2 & 0,01 & $3,91 *$ & 0,01 & 1,71 n.s. & 0,00 & 0,86 n.s. \\
\hline Interação ExVxR & 2 & 0,01 & 2,29 n.s. & 0,02 & 5,72 n.s. & 0,00 & 0,50 n.s. \\
\hline Resíduo (C) & 18 & & & & & & \\
\hline Total & 47 & \multirow{2}{*}{\multicolumn{2}{|c|}{13,46}} & \multirow{2}{*}{\multicolumn{2}{|c|}{12,86}} & \multirow{2}{*}{\multicolumn{2}{|c|}{13,53}} \\
\hline C.V. \% & & & & & & & \\
\hline
\end{tabular}


Tabela 19. Caracteres agronômicos de campo: comprimento do primeiro ramo frutífero $(\mathrm{RF})$, comprimento do ramo frutífero mediano e comprimento do último ramo frutífero. Piracicaba, SP.

\begin{tabular}{|c|c|c|c|}
\hline Tratamentos & $\begin{array}{c}\text { Comprimento do } 1^{\circ} \\
\text { RF (cm) }\end{array}$ & $\begin{array}{l}\text { Comprimento do } \mathbf{R F} \\
\text { mediano }(\mathrm{cm})\end{array}$ & $\begin{array}{c}\text { Comprimento do } \\
\text { último RF }(\mathrm{cm})\end{array}$ \\
\hline $\mathrm{E}_{1}(\mathbf{0 , 7 6 m )}$ & $37,95 \mathrm{~b}$ & 37,66 a & $15,00 \mathrm{~b}$ \\
\hline$E_{2}(1,01 m)$ & $42,41 \mathrm{a}$ & $41,58 \mathrm{a}$ & $16,95 \mathrm{a}$ \\
\hline $\mathbf{F}$ & $43,20 * *$ & 6,57 n.s. & $22,16 *$ \\
\hline C.V. $(\%)$ & 13,45 & 12,86 & 13,52 \\
\hline DMS (5\%) & 2,1 & 4,8 & 1,3 \\
\hline $\mathrm{V}_{1}($ IAC 23) & $42,68 \mathrm{a}$ & $42,06 \mathrm{a}$ & 18,43 a \\
\hline$V_{2}$ (DeltaOpal) & 40,12 a & 38,18 a & $13,93 \mathrm{~b}$ \\
\hline$V_{3}(C D 401)$ & 37,75 a & 38,62 a & $15,56 \mathrm{~b}$ \\
\hline $\mathbf{F}$ & 1,64 n.s. & 1,84 n.s. & $27,69 * *$ \\
\hline C.V. $(\%)$ & 13,45 & 12,86 & 13,52 \\
\hline DMS (5\%) & 7,27 & 5,90 & 1,63 \\
\hline $\mathbf{R}_{1}$ (s/ regulador) & $43,54 \mathrm{a}$ & 42,75 a & $17,04 \mathrm{a}$ \\
\hline $\mathbf{R}_{2}$ (c/ regulador) & $36,83 \mathrm{~b}$ & $36,50 \mathrm{~b}$ & $14,91 \mathrm{~b}$ \\
\hline $\mathbf{F}$ & $18,47 * *$ & $18,05 * *$ & $11,59 * *$ \\
\hline C.V. $(\%)$ & 13,45 & 12,86 & 13,52 \\
\hline DMS (5\%) & 3,28 & 3,09 & 1,31 \\
\hline
\end{tabular}

Médias seguidas da mesma letra na vertical não diferem entre si pelo teste de Tukey, ao nível de 5\% de probabilidade.

\subsection{Caracteres agronômicos de laboratório}

A tabela 21 contém os dados obtidos dos caracteres agronômicos de laboratório (massa média de um capulho, porcentagem de fibras, massa de 100 sementes), assim como os valores de F, do coeficiente de variação e das diferenças mínimas significativas ao nível de $5 \%$ de probabilidade para o teste de 
Tukey. Observa-se apenas o efeito significativo isolado entre as cultivares para os caracteres agronômicos de laboratório estudados. Sendo que não foram observadas interações significativas entre os tratamentos

Tabela 20 - Caracteres agronômicos de campo: Interação cultivar x regulador de crescimento para o comprimento dos ramos frutíferos. Piracicaba, SP.

\begin{tabular}{|c|c|c|c|c|c|c|}
\hline \multirow{2}{*}{$\begin{array}{l}11 \text { Cultivar } \\
\text { es }\end{array}$} & \multicolumn{2}{|c|}{ Comprimento do $1^{\circ} \mathrm{RF}(\mathrm{cm}$} & \multicolumn{2}{|c|}{$\begin{array}{l}\text { Comprimento do RF } \\
\text { mediano }(\mathrm{cm})\end{array}$} & \multicolumn{2}{|c|}{$\begin{array}{l}\text { Comprimento do último RF } \\
(\mathbf{c m})\end{array}$} \\
\hline & s/reg. & c/ reg. & s/ reg. & c/ reg. & s/reg. & c/ reg. \\
\hline 12 IAC 23 & 48,87 a $\mathrm{A}$ & $36,50 \mathrm{~b} \mathrm{~A}$ & 46,75 a $\mathrm{A}$ & 37,37 a $\mathrm{A}$ & 19,50 a $\mathrm{A}$ & 17,37 a $\mathrm{A}$ \\
\hline DeltaOpal & 43,13 a $\mathrm{AB}$ & $37,13 \mathrm{~b} \mathrm{~A}$ & 41,50 a $\mathrm{A}$ & 34,87 a $\mathrm{A}$ & 14,50 a $\mathrm{A}$ & 13,37 a $\mathrm{A}$ \\
\hline CD 401 & 38,62 a B & 36,87 a $\mathrm{A}$ & 40,00 a $\mathrm{A}$ & 37,25 a $\mathrm{A}$ & 17,12 a $\mathrm{A}$ & 14,00 a $\mathrm{A}$ \\
\hline $\mathbf{F}$ & \multicolumn{2}{|c|}{$3,91 * *$} & \multicolumn{2}{|c|}{0,86 n.s. } & \multicolumn{2}{|c|}{ 1,71 n.s. } \\
\hline C.V. $(\%)$ & \multicolumn{2}{|c|}{13,45} & \multicolumn{2}{|c|}{13,53} & \multicolumn{2}{|c|}{12,86} \\
\hline DMS $(5 \%)$ & \multicolumn{2}{|c|}{5,68} & & & & \\
\hline
\end{tabular}

\subsubsection{Massa média de um capulho}

Ao analisar a tabela 22, verificamos que a massa de capulho não foi influenciada pela variação de espaçamentos. Estes resultados estão de acordo com os observados por Belletini (1988). Entretanto, Lamas (1988) e Banci (1992), constataram que espaçamentos mais estreitos induzem a produção de capulhos mais leves, porém nos espaçamentos acima de 0,60 m não observaram diferenças significativas, na massa média do capulho. 
Em relação ao efeito do regulador de crescimento não houve diferenças na massa de capulho com a aplicação deste produto (Tabela 22). Como também observado por Barbosa (1983), Banci (1992) e Carvalho et al. (2001b).

A variação da massa de capulho, apresentada pelas cultivares na tabela 22, é conseqüência das diferenças genéticas de cada cultivar.

\subsubsection{Porcentagem de fibras}

A análise de variância demostrou efeito significativo ao nível $1 \%$ de probabilidade, das cultivares na porcentagem de fibras, porém, os demais tratamentos e suas interações não influenciaram nesta característica, como podemos notar na tabela 21 .

A variação dos espaçamentos adotados no experimento e aplicação de regulador de crescimento não influenciaram na porcentagem de fibra de algodão (Tabela22). Do mesmo modo, Lamas (1988), Belletini (1988), Carvalho et al. (2001b) encontraram resultados semelhantes ao deste trabalho, ou seja, não houve efeito significativo do espaçamento entre fileiras sobre essa característica. Quanto ao efeito do regulador de crescimento, Carvalho et al. (2001b) observaram que a aplicação de cloreto de mepiquat diminuiu a porcentagem de fibras. LacaBuendia (1989) e Athayde \& Lamas (1999), no entanto, não observaram efeito deste produto na porcentagem de fibras.

Na tabela 22, verifica-se que a cultivar DeltaOpal apresentou a maior porcentagem de fibras, diferindo estatisticamente das demais cultivares. Resultados que estão de acordo com os apresentados por Freire \& Farias (2001) em diversos ensaios regionais na região do cerrado, onde a cultivar DeltaOpal destaca-se das demais pela porcentagem de fibras. 
Tabela 21. Quadrado médio (QM), F da análise de variância (F) e coeficiente de variação dos resíduos (CV) referentes aos parâmetros avaliados das características agronômicos de laboratório para espaçamentos (E), cultivares (V), regulador (R) e suas interações (média de 4 repetições). Piracicaba, SP.

\begin{tabular}{|c|c|c|c|c|c|c|c|}
\hline \multirow[b]{2}{*}{ Causas da Variação } & \multirow[b]{2}{*}{ G.L } & \multicolumn{2}{|c|}{$\begin{array}{l}\text { Massa média de um } \\
\text { capulho }(\mathrm{g})\end{array}$} & \multicolumn{2}{|c|}{$\begin{array}{c}\text { Porcentagem de fibras } \\
(\%)\end{array}$} & \multicolumn{2}{|c|}{ Massa de 100 sementes (g) } \\
\hline & & QM & $\mathbf{F}$ & QM & $\mathbf{F}$ & QM & $\mathbf{F}$ \\
\hline Bloco (B) & 3 & & & & & & \\
\hline Espaçamento (E) & 1 & 0,19 & 2,05 n.s. & 0,15 & 0,31 n.s. & 0,01 & 0,03 n.s. \\
\hline Resíduo (A) & 3 & & & & & & \\
\hline Cultivar (V) & 2 & 14,61 & $80,76 * *$ & 27,11 & $24,53 * *$ & 39,19 & $126,44 * *$ \\
\hline Interação ExV & 2 & 0,02 & 0,13 n.s. & 1,75 & 1,58 n.s. & 0,15 & 0,47 n.s. \\
\hline Resíduo (B) & 12 & & & & & & \\
\hline Regulador (R) & 1 & 0,65 & 3,15 n.s. & 1,46 & 1,61 n.s. & 1,05 & 3,36 n.s. \\
\hline Interação ExR & 1 & 0,44 & 2,12 n.s. & 0,62 & 4,52 n.s. & 0,57 & 1,18 n.s. \\
\hline Interação VxR & 2 & 0,87 & 0,42 n.s. & 4,12 & 0,69 n.s. & 0,72 & 2,31 n.s. \\
\hline Interação ExVxR & 2 & 0,28 & 1,39 n.s. & 0,24 & 0,26 n.s. & 0.32 & 1,01 n.s. \\
\hline Resíduo (C) & 18 & & & & & & \\
\hline Total & 47 & \multirow{2}{*}{\multicolumn{2}{|c|}{7,63}} & \multirow{2}{*}{\multicolumn{2}{|c|}{2,50}} & \multirow{2}{*}{\multicolumn{2}{|c|}{4,81}} \\
\hline C.V. \% & & & & & & & \\
\hline
\end{tabular}


A menor porcentagem de fibra obtida pela cultivar IAC 23 pode ser atribuída a maior massa de sementes, o que resultou na menor relação fibra/fibra + sementes. A porcentagem de fibras da cultivar IAC 23 obtida neste trabalho foi inferior à observada por Carvalho et al. (2001a) em estudos realizado com esta cultivar. A porcentagem de fibra da cultivar CD 401, está de acordo com a citação de Penna et al. (2001).

Tabela 22. Caracteres agronômicas de laboratório: Massa média de um capulho, porcentagem de fibras e massa de 100 sementes. Piracicaba, SP.

\begin{tabular}{|c|c|c|c|}
\hline Tratamentos & $\begin{array}{c}\text { Massa média de um } \\
\text { capulho }(\mathrm{g})\end{array}$ & $\begin{array}{c}\text { Porcentagem de } \\
\text { fibras }(\%)\end{array}$ & $\begin{array}{c}\text { Massa de 100 } \\
\text { sementes (g) }\end{array}$ \\
\hline$\overline{E_{1}(0,76 m)}$ & $6,03 \mathrm{a}$ & 38,27 a & $11,66 \mathrm{a}$ \\
\hline $\mathrm{E}_{2}(\mathbf{1 , 0 1 \mathrm { m } )}$ & $5,90 \mathrm{a}$ & 38,16 a & $11,62 \mathrm{a}$ \\
\hline $\mathbf{F}$ & 2,05 n.s. & 0,31 n.s. & 0,03 n.s. \\
\hline C.V. (\%) & 7,63 & 2,49 & 4,80 \\
\hline DMS (5\%) & 0,28 & 0,64 & 0,68 \\
\hline $\mathrm{V}_{1}(\mathrm{IAC} 23)$ & $7,07 \mathrm{a}$ & $37,21 \mathrm{~b}$ & 13,43 a \\
\hline $\mathrm{V}_{2}$ (DeltaOpal) & $5,46 \mathrm{~b}$ & 39,69 a & $10,99 \mathrm{~b}$ \\
\hline$V_{3}(C D 401)$ & $5,37 \mathrm{~b}$ & $37,75 \mathrm{~b}$ & $10,51 \mathrm{~b}$ \\
\hline $\mathbf{F}$ & $80,76 * *$ & $24,53 * *$ & $126,44 * *$ \\
\hline C.V. (\%) & 7,63 & 2,49 & 4,80 \\
\hline DMS $(5 \%)$ & 0,40 & 0,99 & 0,53 \\
\hline$R_{1}$ (s/ regulador $)$ & $6,08 \mathrm{a}$ & 38,39 a & 11,79 a \\
\hline $\mathbf{R}_{2}$ (c/ regulador $)$ & $5,85 \mathrm{a}$ & $38,04 \mathrm{a}$ & $11,50 \mathrm{a}$ \\
\hline $\mathbf{F}$ & 3,15 n.s. & 1,61 n.s. & 3,36 n.s. \\
\hline C.V. (\%) & 7,63 & 2,49 & 4,80 \\
\hline DMS (5\%) & 0,27 & 0,58 & 0,34 \\
\hline
\end{tabular}




\subsubsection{Massa de 100 sementes}

A análise de variância (tabela 21) apresentou efeito significativo das cultivares na massa de 100 sementes, não sendo influenciada no entanto, por nenhum outro tratamento. $\mathrm{O}$ efeito observado deve-se às características intrínsecas das cultivares.

Na tabela 22, nota-se que a massa de 100 sementes foi semelhante para os espaçamentos de 0,76 e 1,01 m. Resultados semelhantes foram obtidos por Banci (1992), nas semeaduras de 30 de novembro e 27 de dezembro, quando não houve efeito dos espaçamentos na massa de sementes. Ainda com relação ao espaçamento entre fileiras sobre esta característica, Lamas (1988), observou que a maior massa de 100 sementes foi encontrado no espaçamento de $0,80 \mathrm{~m}$, que não foi diferente estatisticamente dos espaçamentos de 1,00 e 1,20 m, mas diferiu dos espaçamentos de 30, 40 e $60 \mathrm{~m}$. Entretanto, Souza (1996) verificou a influencia do espaçamento na massa de 100 sementes, caracterizando-se a tendência de menor massa em função do aumento da população. A avaliação da massa de 100 sementes revelou maiores valores para os plantios menos adensados (40.000 planta por hectare). Resultados que estão de acordo com os de Fowler \& Ray (1977), que verificaram redução na massa de 100 sementes quando os espaçamentos entre plantas decresceram.

Verificando a tabela 22, nota-se que não houve diferenças estatísticas entre os tratamentos de regulador de crescimento para esta característica. A aplicação de regulador de crescimento não afetou a massa de 100 sementes. Laca-Buendia (1989) e Athayde \& Lamas (1999) observaram resultados semelhantes ao testar doses de regulador de crescimento. Carvalho et al. (2001), no entanto, verificaram que a aplicação de regulador de crescimento proporcionou aumentos na massa de 100 sementes. Assim como Banci (1992) que observou que o aumento das doses de cloreto de mepiquat, aumentavam a massa de 100 sementes. 
Na tabela 22, observamos, ainda, que as cultivares tiveram influencia na massa de 100 sementes. A cultivar IAC 23 diferiu estatisticamente das demais cultivares. A maior massa de 100 sementes foi encontrada na cultivar que proporcionou menor porcentagem de fibras. A massa de 100 semente da cultivar IAC 23 está de acordo com os resultados apresentados por Carvalho et al. (2001a).

\subsection{Características tecnológicas das fibras}

Não houve influência significativa dos espaçamento sobre as características tecnológicas das fibras (Tabela 23). Segundo Jones e Wells (1997) o espaçamento entre fileiras não influencia nas características tecnológicas da fibra, sendo estas características mais influenciadas pela densidade de plantas na linha de semeadura. Resultados semelhantes foram observados por Nóbrega et al. (1993), Heitholt et al. (1996) e Carvalho et al. (2001b). No entanto Jost e Cother (2001) nos espaçamentos super adensados (0,19 e 0,38 m) observaram diminuição no comprimento da fibra. Porém, nos espaçamentos convencionais $(0,76$ e 1,01 m), esta diminuição não ocorreu e não foram verificadas diferenças significativas para as demais características de qualidade de fibra.

Diferenças estatísticas foram verificadas entre as cultivares quanto às características tecnológicas da fibra (Tabela 24). A cultivar CD 401 destaca-se positivamente das demais quanto à uniformidade e tenacidade. As cultivares IAC 23 e DeltaOpal foram superiores a CD 401 quanto a maturidade da fibra e no índice micronoaire. $\mathrm{O}$ menor índice micronaire observado na cultivar CD 401 pode estar associado à mais baixa maturidade da fibra. Quanto ao comprimento de fibra, as cultivares são equivalentes, enquadram-se como produtoras de fibra de comprimento médio. 
Tabela 23. Quadrado médio (QM), F da análise de variância (F) e coeficiente de variação dos resíduos (CV) referentes aos parâmetros avaliados das características tecnológicas das fibras para espaçamentos (E), cultivares (V), regulador (R) e suas interações (média de 4 repetições). Piracicaba, SP.

\begin{tabular}{|c|c|c|c|c|c|c|c|c|c|c|c|}
\hline \multirow[b]{2}{*}{$\begin{array}{l}\text { Causas da } \\
\text { Variação }\end{array}$} & \multirow[b]{2}{*}{ G L } & \multicolumn{2}{|c|}{$\begin{array}{l}\text { Comprimento da } \\
\text { fibra (mm) }\end{array}$} & \multicolumn{2}{|c|}{ Uniformidade (\%) } & \multicolumn{2}{|c|}{ Maturidade (\%) } & \multicolumn{2}{|c|}{ Tenacidade (g/Tex) } & \multicolumn{2}{|c|}{ Micronaire (mm) } \\
\hline & & $\mathbf{Q M}$ & $\mathbf{F}$ & $\mathbf{Q M}$ & $\mathbf{F}$ & QM & $\mathbf{F}$ & QM & $\mathbf{F}$ & $\mathbf{Q M}$ & $\mathbf{F}$ \\
\hline Espaç. (E) & 1 & 0,24 & 0,46 n.s. & 4,75 & 3,22 n.s. & 7,13 & 8,79 n.s. & 0,00 & 0,00 n.s. & 0,11 & 1,65 n.s. \\
\hline Resíduo (A) & 3 & & & & & & & & & & \\
\hline Cultivar (V) & 2 & 1,36 & 2,81 n.s. & 19,28 & $31,33 * *$ & 43,59 & $10,18 * *$ & 17,76 & $21,13 * *$ & 0,56 & $11,96 * *$ \\
\hline Regulador (R) & 1 & 0,00 & 0,01 n.s. & 0,46 & 0,84 n.s. & 0,77 & 0,38 n.s. & 0,19 & 0,26 n.s. & 0,15 & $9,55 * *$ \\
\hline Interação ExR & 1 & 0,48 & 1,35 n.s. & 0,05 & 0,09 n.s. & 0,58 & 0,29 n.s. & 1,40 & 1,93 n.s. & 0,01 & 0,33 n.s. \\
\hline Interação VxR & 2 & 0,52 & 1,48 n.s. & 0,62 & 1,13 n.s. & 1,24 & 0,61 n.s. & 2,94 & $4,04 *$ & 0,02 & 1,10 n.s. \\
\hline Inter. ExVxR & 2 & 0,02 & 0,06 n.s. & 1,43 & 0,65 n.s. & 3,38 & 1,66 n.s. & 2,67 & $3,67 *$ & 0,01 & 0,84 n.s. \\
\hline Resíduo (C) & 18 & & & & & & & & & & \\
\hline Total & 47 & & & & & & & & & & \\
\hline
\end{tabular}


Tabela 24. Comprimento da fibra $(\mathrm{mm})$, uniformidade $(\%)$, maturidade $(\%)$, tenacidade $(\mathrm{g} / \mathrm{Tex})$ e micronaire (mm) referentes aos parâmetros avaliados das características tecnológicas da fibra para espaçamentos (E), cultivares (V), regulador (R) e suas interações (média de 4 repetições). Piracicaba, SP.

\begin{tabular}{|c|c|c|c|c|c|}
\hline Tratamentos & $\begin{array}{l}\text { Comprimento da } \\
\text { fibra (mm) }\end{array}$ & Uniformidade (\%) & Maturidade (\%) & Tenacidade (g/Tex) & Micronaire (mm) \\
\hline$\overline{E_{1}(0,76 m)}$ & $27,93 \mathrm{a}$ & $47,12 \mathrm{a}$ & $73,54 \mathrm{a}$ & $26,81 \mathrm{a}$ & $4,42 \mathrm{a}$ \\
\hline$E_{2}(1,01 m)$ & $28,07 \mathrm{a}$ & 46,49 a & 72,77 a & $26,80 \mathrm{a}$ & 4,33 a \\
\hline $\mathbf{F}$ & 0,46 n.s. & 3,22 n.s. & 8,79 n.s. & 0,00 n.s. & 1,65 n.s. \\
\hline C.V. (\%) & 2,13 & 1,58 & 1,95 & 3,18 & 2,88 \\
\hline DMS (5\%) & 0,66 & 1,12 & 0,83 & 1,26 & 0,23 \\
\hline $\mathrm{V}_{1}(\mathrm{IAC} 23)$ & 27,93 a & $46,75 \mathrm{~b}$ & 74,55 a & $26,25 \mathrm{~b}$ & 4,48 a \\
\hline $\mathrm{V}_{2}$ (DeltaOpal) & 27,76 a & $45,73 \mathrm{c}$ & 73,57 a & $26,14 \mathrm{~b}$ & 4,48 a \\
\hline$V_{3}(C D 401)$ & 28,32 a & 47,93 a & $71,33 \mathrm{~b}$ & 28,14 a & $4,16 \mathrm{~b}$ \\
\hline $\mathbf{F}$ & 2,81 n.s. & $31,33 * *$ & $10,18 * *$ & $21,13 * *$ & $11,97 * *$ \\
\hline C.V. $(\%)$ & 2,13 & 1,58 & 1,95 & 3,18 & 2,88 \\
\hline DMS (5\%) & 0,66 & 0,74 & 1,96 & 0,87 & 0,20 \\
\hline $\mathrm{R}_{1}$ (s/ regulador) & $28,01 \mathrm{a}$ & $46,90 \mathrm{a}$ & 73,06 a & 26,86 a & 4,43 a \\
\hline $\mathbf{R}_{2}$ (c/ regulador) & $28,00 \mathrm{a}$ & $46,70 \mathrm{a}$ & 73,28 a & 26,74 a & $4,32 \mathrm{~b}$ \\
\hline $\mathbf{F}$ & 0,01 n.s. & 0,84 n.s. & 0,38 n.s. & 0,26 n.s. & $9,55 * *$ \\
\hline C.V. (\%) & 2,13 & 1,58 & 1,95 & 3,18 & 2,88 \\
\hline DMS (5\%) & 0,36 & 0,45 & 0,86 & 0,52 & 0,08 \\
\hline
\end{tabular}

Médias seguidas da mesma letra na vertical não diferem entre si pelo teste de Tukey, ao nível de 5\% de probabilidade. 
O regulador de crescimento, confirmando os resultados observados por Banci (1992), não influenciou na maioria da características tecnológicas das fibras. Verificam-se alterações apenas no índice Micronaire (Tabela 24), com a aplicação do cloreto de mepiquat, reduzindo significativamente a finura da fibra. Contrário a este resultado Carvalho et al. (2001b) observou o aumento deste índice com a aplicação do regulador de crescimento. Tal fato pode estar associado ao efeito provocado na redução da maturidade da fibra verificado na cultivar CD 401.

Resultados contraditórios são observados na literatura a respeito da aplicação de regulador de crescimento e índice Micronaire. York (1983), LacaBuendia (1989), Cia et al. (1996) e Athayde \& Lamas (1999), em diversos estudos realizados em diferentes condições, não observaram efeitos significativos da aplicação deste produto, no índice Micronaire.

Tabela 25. Características tecnológicas da fibra - Interação cultivar x regulador de crescimento para Tenacidade (g/Tex). Piracicaba, SP.

\begin{tabular}{lcc}
\hline \multirow{2}{*}{ Cultivares } & \multicolumn{2}{c}{ Tenacidade (gf/Tex) } \\
& s/ reg. & c/ reg. \\
\hline 14 IAC 23 & 26,30 a B & 26,21 a B \\
DeltaOpal & 26,64 a AB & 25,64 a B \\
CD 401 & 27,66 a A & 28,38 a A \\
F & & $4,04 *$. \\
C.V. $(\%)$ & 18,13 \\
DMS $(\%)$ & & 1,36 \\
\end{tabular}

*,** Significativos aos níveis de 5 e $1 \%$ respectivamente pelo teste de $\mathrm{F}$ da análise da variância.

Médias seguidas da mesma letra maiúscula, na vertical, não diferem entre si pelo teste de Tukey, ao nível de 5\% de probabilidade.

Médias seguidas da mesma letra minúscula , na horizontal, não diferem entre si pelo teste de Tukey, ao nível de 5\% de probabilidade. 
A tenacidade da fibra que representa a resistêncai desta, foi a característica que se mostrou mais influenciável pelos tratametno (Tabela 23). As cultivares estudadas, como efeito isolado, apresentaram difernças significativas entre si, com destaque superior para a cultivar CD 401. Não sendo esta característica influenciada pela variação do espaçamento e pelo uso do regulador de crescimento na média do ensaio. Porém verifica-se o efeito significativo da interação cultivar x regulador de crescimento (Tabela 25). Neste caso, a cultivar CD 401 mostrou-se favorecida pelo uso do regulador de crescimetno comparada com as outras duas cultivares. No entanto, não diferindo da cultivar DeltaOpal quando houve aplicação do produto.

Tabela 26. Características tecnológicas da fibra: Tenacidade (gf/Tex) - Interação espaçamento x cultivar x regulador de crescimento. Piracicaba, SP.

\begin{tabular}{lc}
\hline Tratamentos & Tenacidade (g/Tex) \\
\hline IAC 23 /Esp. 0,76m/Sem Reg. & $26,47 \mathrm{abc}$ \\
IAC 23 /Esp. 0,76m/Com Reg. & $26,15 \mathrm{bc}$ \\
IAC 23 /Esp. 1,01m/Sem Reg. & $26,13 \mathrm{bc}$ \\
IAC 23 /Esp. 1,01m/Com Reg. & $26,20 \mathrm{abc}$ \\
DeltaOpal/Esp. 0,76m/Sem Reg. & $26,08 \mathrm{bc}$ \\
DeltaOpal /Esp. 0,76m/Com Reg. & $26,35 \mathrm{abc}$ \\
DeltaOpal /Esp. 1,01m/Sem Reg. & $27,20 \mathrm{ab}$ \\
DeltaOpal /Esp. 1,01m/Com Reg. & $24,93 \mathrm{c}$ \\
CD 401/Esp. 0,76m/Sem Reg. & $27,55 \mathrm{ab}$ \\
CD 401/Esp. 0,76m/Com Reg. & $28,25 \mathrm{ab}$ \\
CD 401/Esp. 1,01m/Sem Reg. & $27,78 \mathrm{ab}$ \\
CD 401/Esp. 1,01m/Com Reg. & $28,50 \mathrm{a}$ \\
F & $3,67 *$. \\
C.V. (\%) & 3,18 \\
DMS (5\%) & 2,23 \\
\hline Médias seguidas da mesma letra não diferem entre si pelo teste de Tukey, ao nível de 5\% de probabilidade.
\end{tabular}


$\mathrm{Na}$ interação espaçamento $\mathrm{x}$ cultivar $\mathrm{x}$ regulador de crescimento, nota-se que esta característica foi afetada de forma diferente em cada cultivar (Tabela 26). A cultivar DeltaOpal, no espaçamento mais largo, com aplicação de regulador de crescimento, foi prejudicada e apresentou a menor média (24,93 gf/Tex) para esta característica. Entretanto a cultivar CD 401, quando tratada com regulador de crescimento apresentou as melhores médias para esta característica para ambos espaçamento, não diferindo no entanto dos tratamentos sem regulador. A cultivar IAC 23 não alterou o seu comportamento na presença ou ausência do regulador de crescimento nos espaçamentos estudados, para esta característica. 


\section{CONCLUSÕES}

Considerando as condições experimentais, pode-se concluir que:

a) A soma calórica, da semeadura à abertura do primeiro capulho, para as cultivares CD 401, DeltaOpal e IAC 23 foi de aproximadamente 1170, 1235 e 1246 graus-dia, respectivamente.

b) Quanto a produção de algodão em caroço, cultivares menos competitivas apresentam melhor capacidade adaptativa em densidade populacional mais altas.

c) As cultivares avaliadas, independente da arquitetura das plantas e da aplicação de regulador de crescimento, apresentaram capacidade de ajustar-se às variações de espaçamentos testadas para produção de algodão em caroço.

d) A pressão populacional, principalmente por luz, água e nutrientes, exercida nos espaçamentos utilizados, interferiu de forma similar no porte e na altura final das plantas, independente da arquitetura das cultivares, em ambos os espaçamentos.

e) Quanto a altura final das plantas, evidencia-se a necessidade de adequação de doses de regulador de crescimento, dependendo da cultivar e do espaçamento adotado.

f) A redução do diâmetro de caule foi mais expressiva nas cultivares de desenvolvimento mais vigoroso com a redução do espaçamento e aplicação do regulador de crescimento, tornando-as mais suscetíveis ao acamamento. A cultivar de plantas mais compactas, não sofreu influência dos tratamentos adotados. 
g) A redução do espaçamento entre fileiras e a aplicação de regulador de crescimento reduziu o número médio de capulhos por planta e o comprimento dos ramos frutíferos. A altura de inserção do primeiro ramo frutífero foi semelhante para as cultivares estudadas, independentemente da arquitetura de cada cultivar.

h) Apesar do regulador de crescimento reduzir o porte das plantas, este não influenciou na altura de inserção do primeiro ramo frutífero, o que caracteriza a formação de plantas mais compactas. A altura de inserção do primeiro ramo frutífero, interfere na colheita mecânica e na qualidade de fibra.

i) A massa média de um capulho, porcentagem de fibra e massa de 100 sementes, foram semelhantes para os tratamentos adotados, apresentando diferenças somente entre as cultivares, respeitando-se as características intrínsecas da cultivar. Assim como para as características tecnológicas das fibras, com exceção da tenacidade. 
ANEXO 


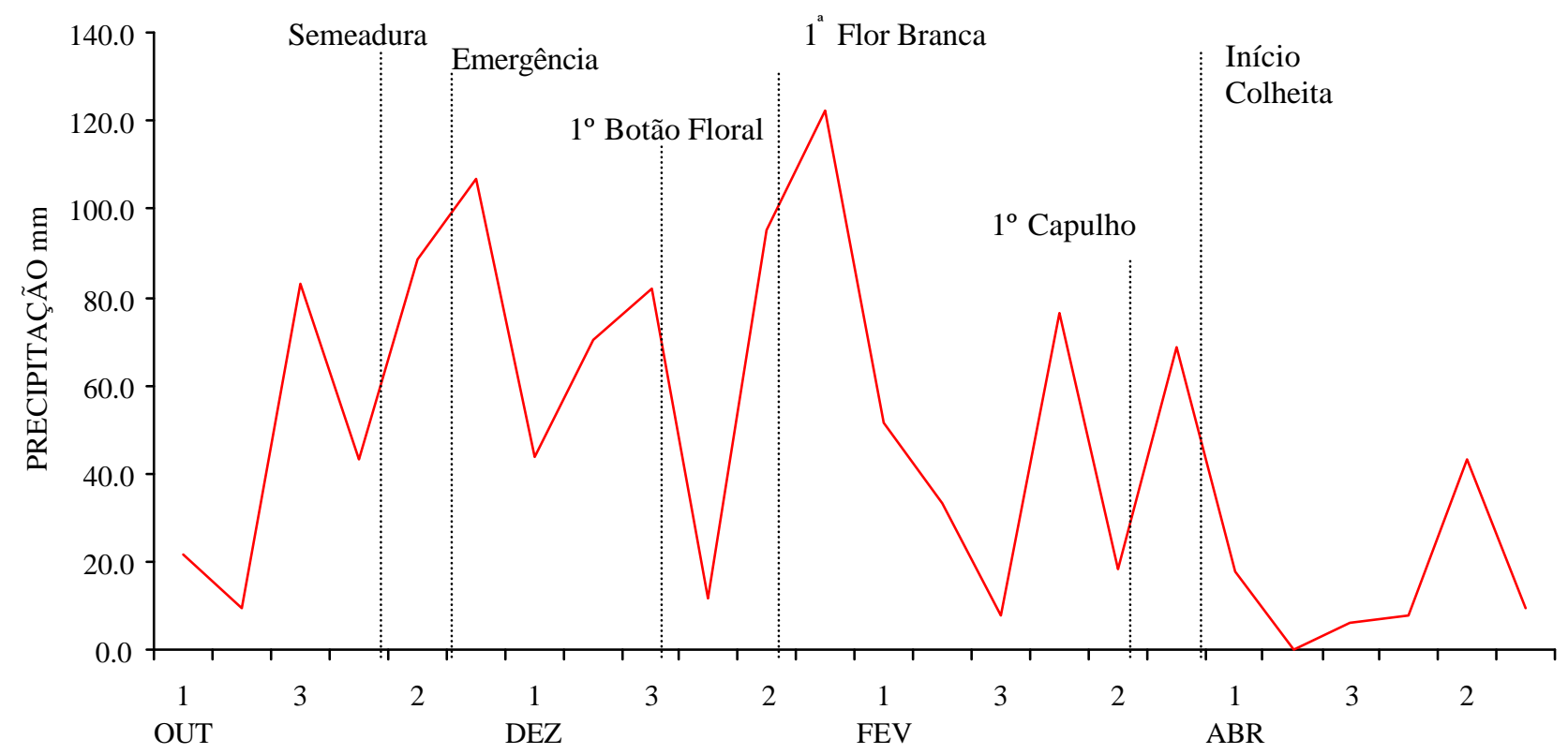

Figura 1 - Distribuição acumulada de chuvas, em cada decênio, durante o período de outubro de 2000 a maio de 2001. Piracicaba, SP.

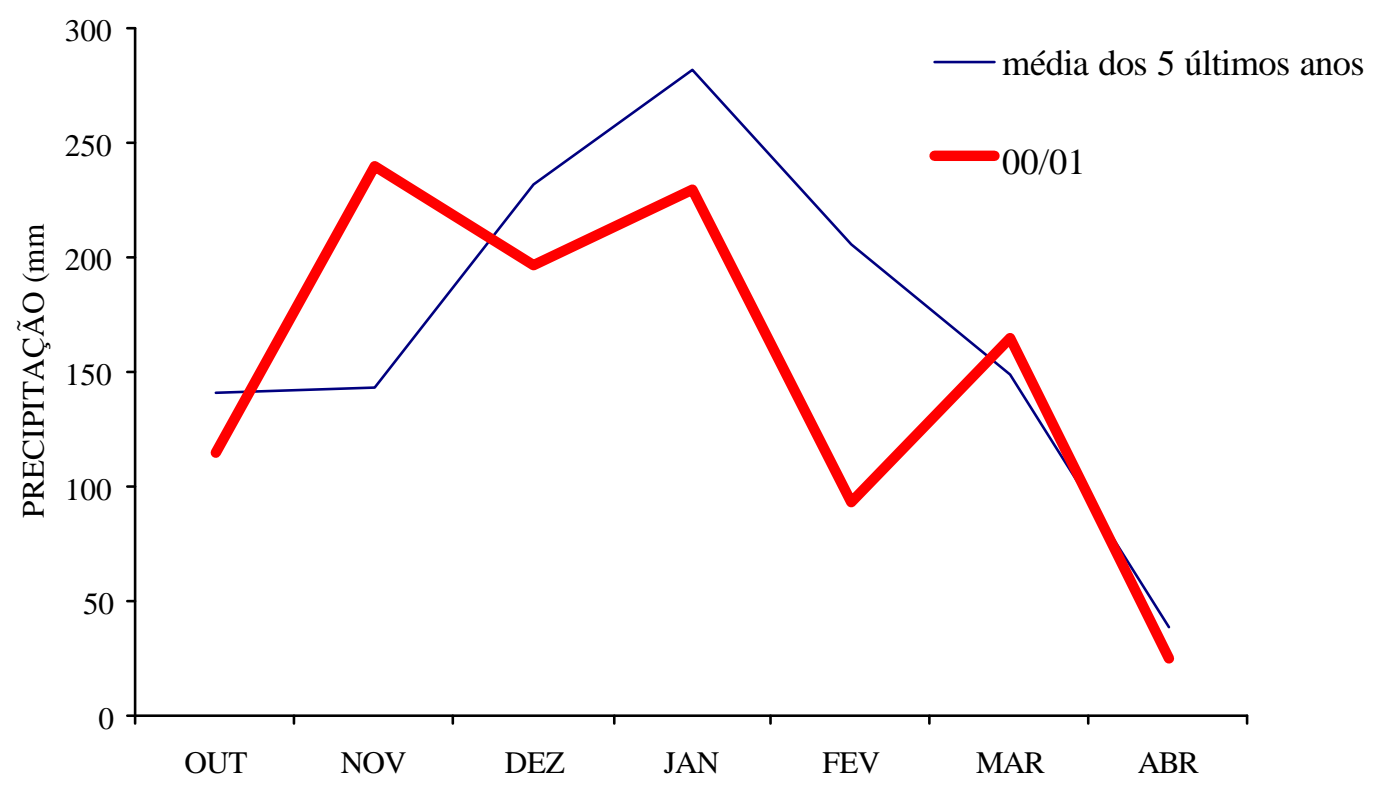

Figura 2 - Distribuição de chuvas durante o período de outubro de 2000 a maio de 2001 e médias de precipitações acumuladas nos últimos cinco anos. Piracicaba, SP. 


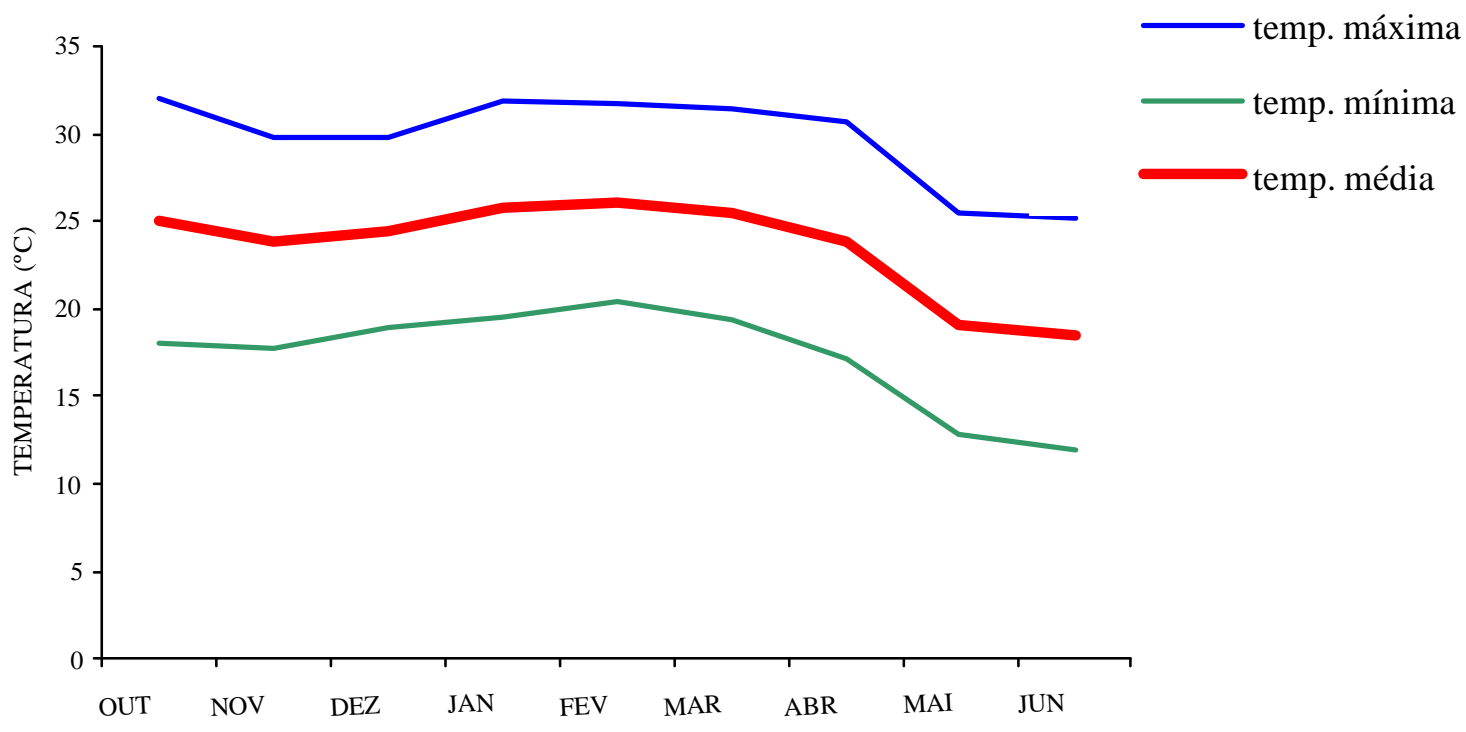

Figura 3 - Temperaturas máxima, mínima e média, ocorridas no período de outubro de 2000 a junho de 2001. Piracicaba, SP.

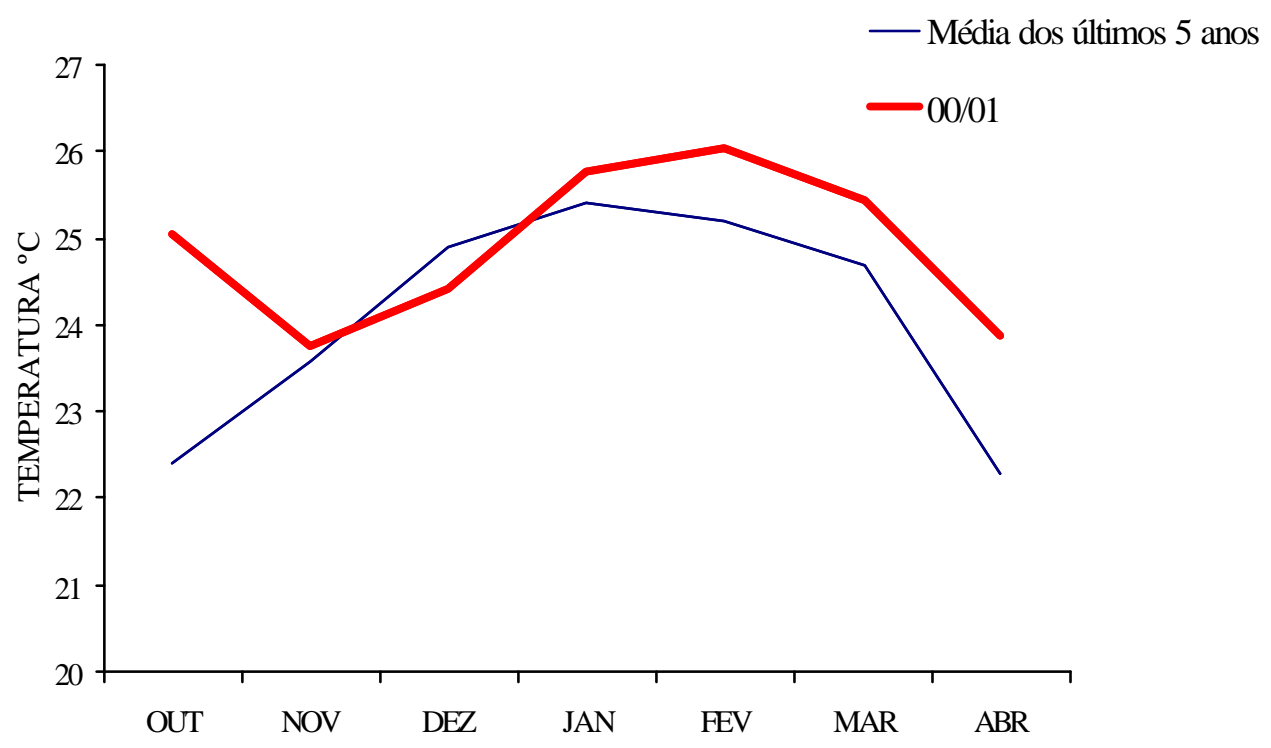

Figura 4 - Temperaturas médias ocorridas no período de outubro de 2000 a junho de 2001 e média da temperatura dos últimos cinco anos. Piracicaba, SP. 


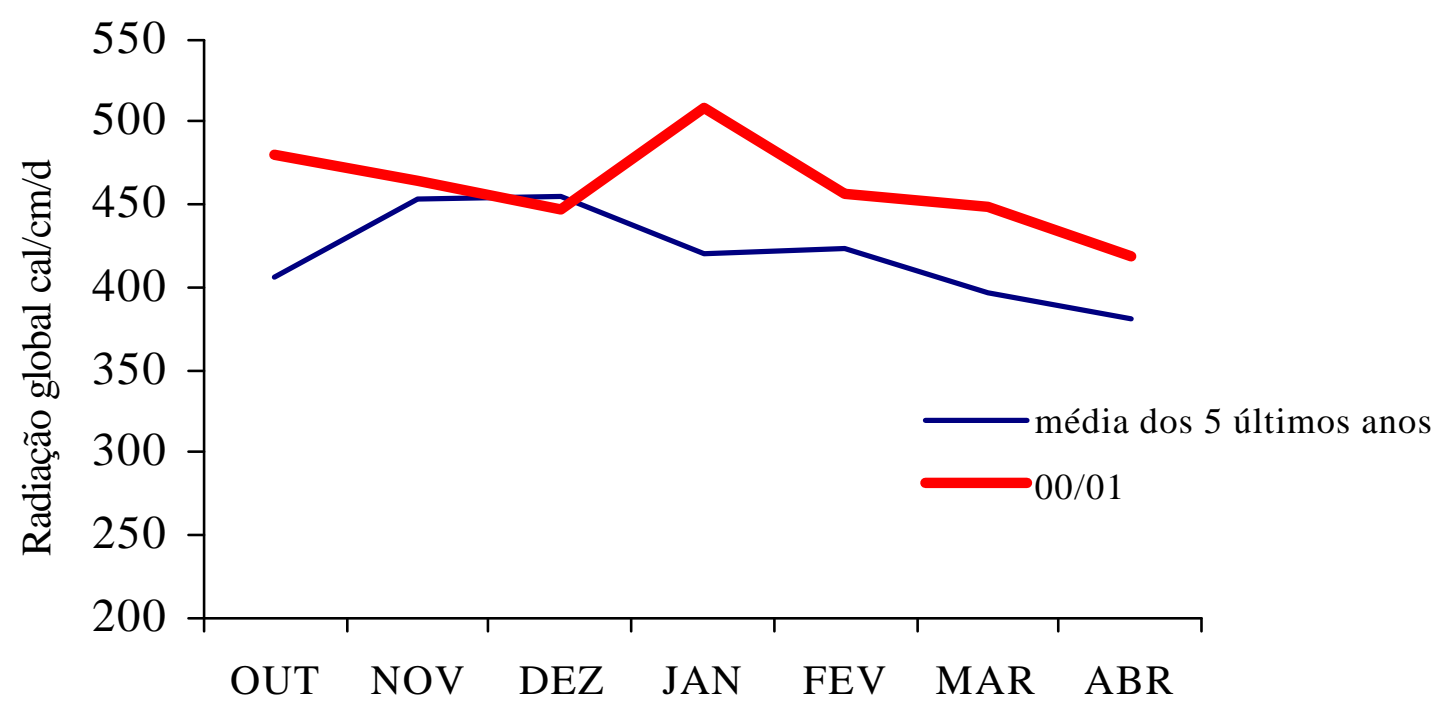

Figura 5 - Radiação Global (cal/cm.d), no período de outubro de 2000 a junho de 2001. Piracicaba, SP.

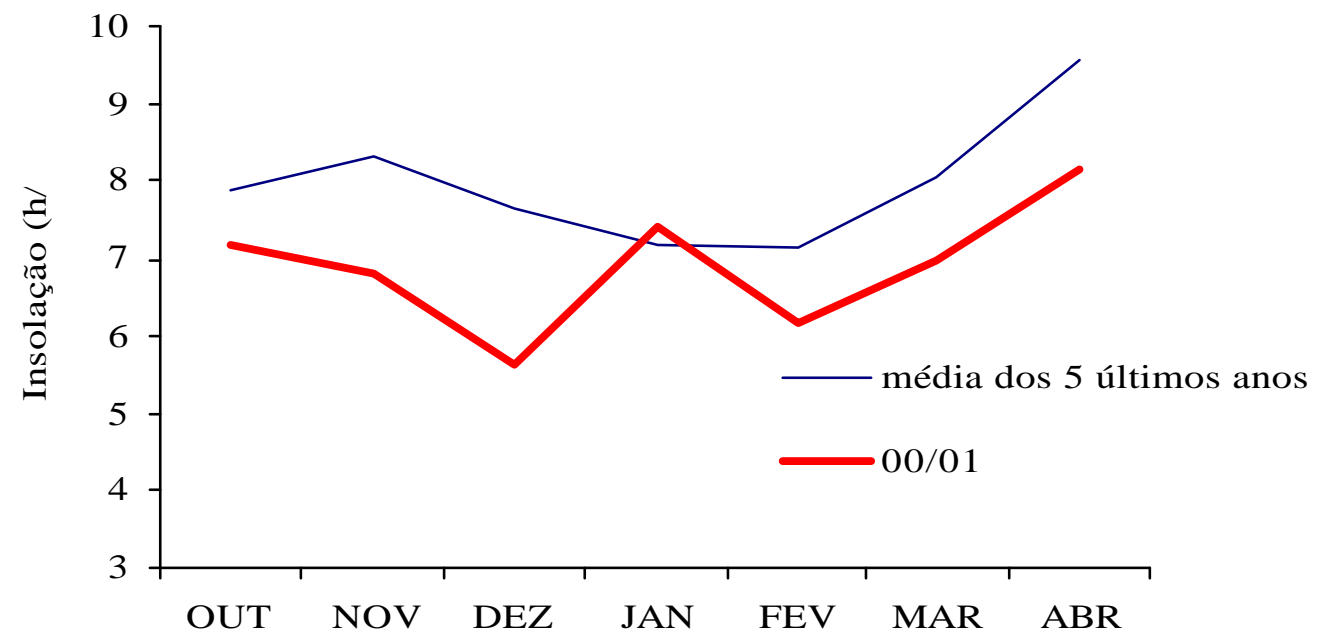

Figura 6 - Insolação (h/d), no período de outubro de 2000 a abril de 2001. Piracicaba, SP. 


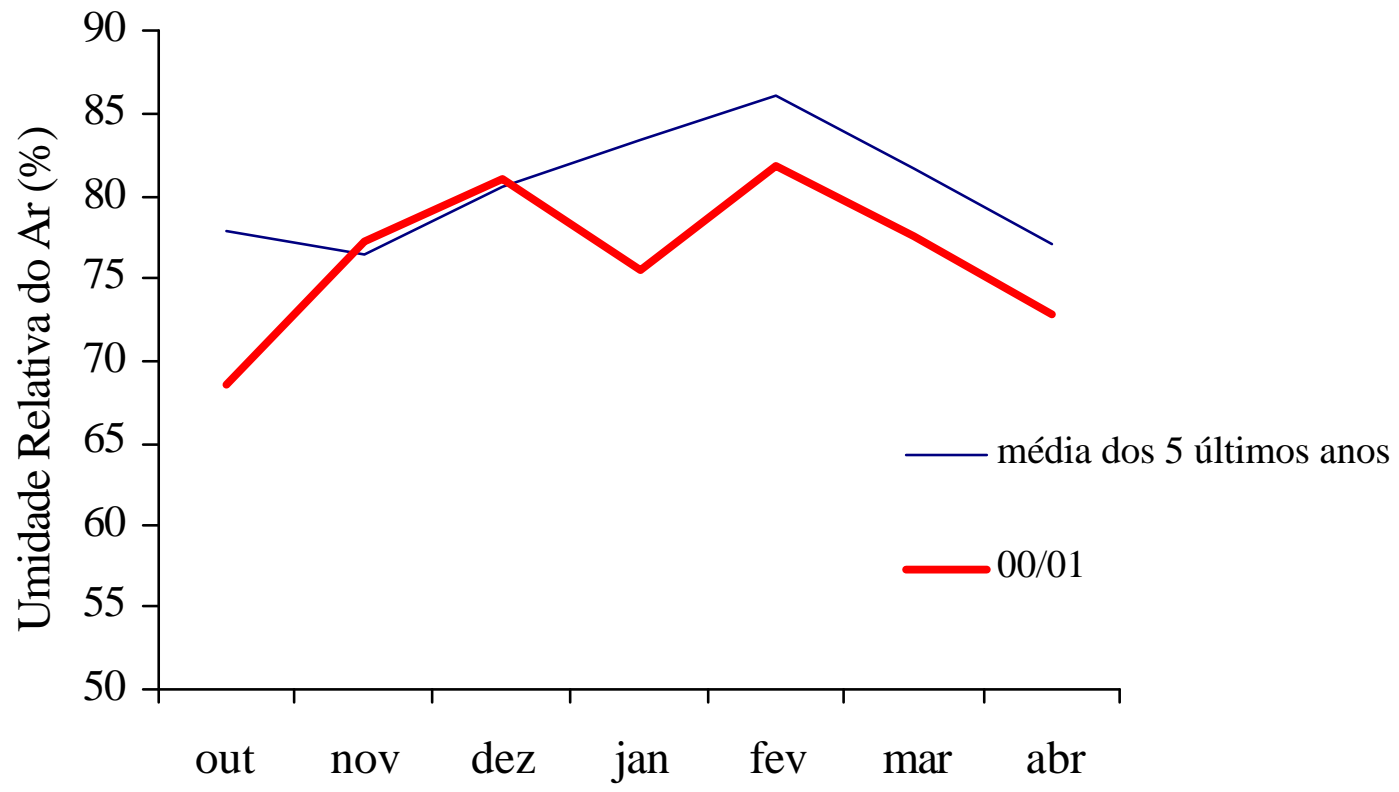

Figura 7 - Umidade relativa do ar e média mensal, no período de outubro de 2000 a junho de 2001. Piracicaba, SP. 


\section{REFERÊNCIAS BIBLIOGRÁFICAS}

FNP - CONSULTORIA \& COMÉRCIO - AGIANUAL 2002: anuário da agricultura brasileira. São Paulo, 2001. p. 141-154: Algodão.

ALLEN, C.T.; KENNEDY, C.; ROBERTSON, B.; KHARBOUTLI, M.; BRYANT, K.; CAPPS, C.; EARNEST, L. Potential of ultra narrow row cotton in Southeast Arkansas. In: PROCEEDINGS BELTWIDE COTTON CONFERENCE. San Diego, 1998. Proceedings. Memphis: National Cotton Council of America, 1998. p. 1403.

ATHAYDE, M.L.F.; LAMAS, M.F. Aplicação seqüencial de cloreto de mepiquat em algodoeiro. Pesquisa Agropecuária Brasileira. v. 34, n.3, p. 369-375, mar., 1999.

BANCI, C.A. Espaçamento entre fileiras e doses de regulador de crescimento cloreto de mepiquat, em três épocas de plantio, na cultura do algodoeiro herbáceo. Viçosa, 1992. 81p. Dissertação (M.S.) - Universidade Federal de Viçosa.

BARBOSA, F.M. Efeito de reguladores vegetais em algodoeiro (gossypium hirsutum L.). Piracicaba, 1983. 97p. Dissertação (Mestrado) - Escola Superior de Agricultura “Luiz de Queiroz”, Universidade de São Paulo. 
BARBOSA, L.M.; CASTRO, P.R.C. Alguns efeitos de reguladores de crescimento na morfologia do algodoeiro (Gossypium hirsutum L. cv. IAC-17). Hoehnea, v.11, p. 59-65, 1984.

BELLETTINI, S. Comportamento do Algodão 'IAC - 20' (gossypium hirsutum L. raça latifolium) em diferentes espaçamentos e distribuições espaciais. Piracicaba, 1988. 101p. Dissertação (M.S.) - Escola Superior de Agricultura "Luiz de Queiroz", Universidade de São Paulo.

BELTRÃO, N.E.M.; SOUZA, J.G. de. Fisiologia e ecofisiologia do algodoeiro. In: Empresa Brasileira de pesquisa Agropecuária. Algodão: tecnologia de produção. Dourados: Embrapa Agropecuária do Oeste, 2001. p. 54-75.

BELTRÃO, N.E.M.; SOUZA, J.G. de; GUERRA, J.S.; TAKIZAWA, E. Manejo cultural do algodoeiro herbáceo na região do cerrado. In: FARIAS, F.J.C.; AGUIAR, P.H.; FREIRE, E.C.; HIROMOTO, D.M. (Ed.) Mato Grosso: liderança e competitividade. Rondonópolis: Fundação MT, 1999. p. 70-86 (Fundação MT. Boletim, 3)

BOLONHEZI, A.C. Remoção da gema apical da haste principal e a aplicação de reguladores de crescimento em algodoeiro herbáceo 'IAC 20'. In: CONGRESSO BRASILEIRO DE ALGODÃO, 1., Fortaleza, 1997. Anais. Campina Grande: EMBRAPA, CNPA, 1997. p. 48-50.

CARVALHO, L.H.; CHIAVEGATO, E.J.; CIA, E.; KONDO, J.I.; ERISMANN, N.M. Efeito do espaçamento e da densidade de plantas na cultivar IAC 23. In: CONGRESSO BRASILEIRO DE ALGODÃO, 3., Campo Grande, 2001. Anais. Campina Grande: Embrapa Algodão; Campo Grande: UFMS; Dourados: Embrapa Agropecuária Oeste, 2001a. p.642-643. 
CARVALHO, L.H.; SILVA, N.M. da; CHIAVEGATO, E.J.; CIA, E.; SABINO, N.P.; KONDO, J.I.; FURLANI Jr., E.; GALLO, B.; PETTINELLI Jr., A. Efeito do cloreto de mepiquat e do espaçamento em cultivares de algodoeiro. In: CONGRESSO BRASILEIRO DE ALGODÃO, 3., Campo Grande, 2001. Anais. Campina Grande: Embrapa Algodão; Campo Grande: UFMS; Dourados: Embrapa Agropecuária Oeste, 2001b. p. 484-487.

CARVALHO, L.P. Contribuição do melhoramento ao cultivo do algodão no Brasil. In: BELTRÃO, N.E.M. O agronegócio do algodão no Brasil. Brasília: Embrapa, Comunicações para Transferência de Tecnologia, 1999. v. 1, p. 251-269.

CAWLEY, N.; EDMISTEN, K.L.; STEWART, M.A.; WELLS, R. Evolution of ultra narrow row cotton in North Carolina. In: PROCEEDINGS BELTWIDE COTTON CONFERENCE. San Diego, 1998. Proceedings. Memphis: National Cotton Council of America, 1998. p. 1402-1403.

CIA, E.; ALLEONI, L.R.F.; FERRAZ, C.A.M.; FUZATTO, M.G.; CARVALHO, L.H.; CHIAVEGATO, E.J.; SABINO, N.P. Densidade de plantio associada ao uso de regulado de crescimento na cultura do algodoeiro. Bragantia, v. $55 \mathrm{n}$. 2, p. 309-316, 1996.

CHIAVEGATO, E.J. Efeito do ambiente e de cultivares nos componentes da produção e nas características tecnológicas da fibra e do fio de algodão. Piracicaba, 1995. 115p. Tese (Doutorado) - Escola Superior de Agricultura “Luiz de Queiroz”, Universidade de São Paulo. 
FREIRE, E.C.; FARIAS, F.J.C. de. Cultivares de algodão para o centro-oeste. . In: Empresa Brasileira de Pesquisa Agropecuária. Algodão: Tecnologia de Produção. Dourados: Embrapa Agropecuária do Oeste, 2001. p. 159-180.

FOWLER, J.L.; RAY, L.L Response of two cotton genotypes to five equidistant spacing patterns. Agronomy Journal. v. 69, n. 5, p.733-738, set./oct., 1977.

FUZATTO, M.G. Objetivos e resultados obtidos nos trabalhos de pesquisa conduzidos no Instituto Agronômico de Campinas com respeito à qualidade de fibra de algodão. In: CONFERÊNCIA NACIONAL DE TECNOLOGIA TÊXTIL, 4, Rio de Janeiro, CETICT/SENAI, 1987. 28p.

GERIK, T.J.; LEMON, R.G.; FAVER, K.L.; HOELEWYN, T.A.; JUNGMAN, M. Performance of ultra-narrow row cotton in Central Texas. In: PROCEEDINGS BELTWIDE COTTON CONFERENCE. San Diego, 1998. Proceedings. Memphis: National Cotton Council of America, 1998 p. 1384.

GOMES, F.P. Curso de estatística experimental. 13 ed. Piracicaba: Nobel. 1990. $467 \mathrm{p}$.

GRIDI-PAPP, I.L.; CIA, E.; FUZATTO, M.G.; SILVA, N.M. da; FERRAZ, C.A.M.; CARVALHO, N. de; CARVALHO, L.H.; SABINO, N.P.; KONDO, J.J.; PASSO, S.M.G.; CHIAVEGATO, G.I.; CAMARGO, P.P. de; CAVALERI, P.A. Manual do produtor de algodão. São Paulo: Bolsa de Mercadorias \& Futuros, 1992. 158p.

HEARN, A.B. Cotton spacing experiments in Uganda. Journal of Agricultural Schience., v.78, p.13-25, 1971. 
HEITHOLT, J.J.; MEREDITH, W.R.; WILlIFORD, J.R. Comparison of cotton genotypes in canopy characteristics in $76-\mathrm{cm}$ vs. 102-cm rows. Crop Science, v. 36, p.955-960. jul./aug. 1996.

HOLLIDAY, R. Plant population and crop yield: part I. Field Crop Abstracts, v.13. p. $159-167,1960$.

JONES, M.A.; WELLS, R. Dry matter allocation and fruit patterns of cotton grow at two divergent plant populations. Crop Science, v.37, n.3, p. 797-802. may/june, 1997.

JOST, P.H.; COTHREN, T.J.; GERIK, T.L. Growth and yield of ultra-narrow row and conventionally spaced cotton. In: PROCEEDINGS BELTWIDE COTTON CONFERENCE. San Diego, 1998. Proceedings. Memphis: National Cotton Council of America, 1998, p. 138.

JOST, P.H.; COTHREN, T.J. Growth and yield of cotton planted in conventional and ultra-narrow row spacings. Crop Science. v. 40, p. 430-435, mar./apr. 2000.

JOST, P.H.; COTHREN, T.J. Phenotypic alterations and crop maturity differences in ultra-narrow row and conventional spaced cotton. Crop Science. v. 41, p. 1150-1159. jul./aug. 2001.

LACA-BUENDIA, J.P.C.; FARIAS, E.A. Manejo e tratos culturais do algodoeiro. Informe Agropecuário, v. 8, n. 92. p.50-61, ago., 1982.

LACA-BUENDIA, J.P. Efeito de doses de regulador de crescimento m algodoeiro (Gossypium hirsutum L.). Revista Brasileira de Fisiologia Vegetal. v.1, n. 1, p. $109-113,1989$. 
LAMAS, F.M. Estudo da interação espaçamento entre fileiras x época de plantio na cultura do algodoeiro herbáceo (Gossypium hirsutum L.). Viçosa, 1988. 64p. Dissertação (M.S.) - Universidade Federal de Viçosa.

LAMAS, F.M. Cloreto de mepiquat, thidiazuron e ethephon aplicados no algodoeiro (Gossypium hirsutum L.), Ponta Porã - MS. Jaboticabal, 1997. 129p. Tese (Doutorado) - Escola Superior de Agricultura "Luiz de Queiroz", Universidade de São Paulo.

LAMAS, F.M.. Reguladores de crescimento. In: Empresa Brasileira de Pesquisa Agropecuária. Algodão: Tecnologia de Produção. Dourados: Embrapa Agropecuária do Oeste, 2001. p. 238-244.

LAMAS, F.M.; STAUT, L.A. Espaçamento e densidade. In: Empresa Brasileira de Pesquisa Agropecuária. Algodão: Tecnologia de Produção. Dourados: Embrapa Agropecuária do Oeste, 2001. p. 135-139.

LAMAS, F.M.; VIEIRA, J.M.; BEGAZO, J.C.E.O; SEDIYAMA, C.S. Estudo da interação entre fileiras e épocas de plantio na cultura do algodoeiro herbáceo (Gossypium hirsutum L.). Revista Ceres, v.36, n. 205, p.247-263, mai./jun., 1989.

LAMAS, F.M.; ATHAYDE, M.L.; BANZATTO, D.A. Reações do algodoeiro CNPA-ITA 90 ao cloreto de mepiquat. Pesquisa Agropecuária Brasileira. v. 35, n. 5, p. 507- 516, mar., 2000.

KITTOCK, D.L.; SELLEY, R.A.; CAIN, C.J.; TAYLOR, B.B. Plant population and plant height effects on pina cotton lint yield. Agronomy Journal. v. 78, p. 534-538. may/june, 1986. 
MAAS, S.J. Competition among equally spaced cotton plants grown at four plant population densities. In: PROCEEDINGS BELTWIDE COTTON CONFERENCE. San Diego, 1997. Proceedings. Memphis: National Cotton Council of America, 1997. p. 1485.

MOHAMED, K.B.; SAPPENFIELD, W.P. PEHLMAN, J.M. Cotton cultivar responses to plant populations in short-season, narrow-row cultural system. Agronomy Journal, v. 74, n. 5, p.619-624. set./oct., 1982.

NÓBREGA, B.N. da; VIERIA, D.J.; BELTRÃO, N.E.M.; AZEVEDO, D.M.P. de. Hormônios e reguladores de crescimento e desenvolvimento. In: BELTRÃO, N.E.M. O Agronegócio do algodão no Brasil. Brasília: Embrapa Comunicações para Transferência de Tecnologia, 1999. V. 2, p. 587-602.

NÓBREGA， L.B. da; BELTRÃO, N.E.M.; VIEIRA, J.V.; DINIZ, M.S.; AZEVEDO, D.M.P. de. Influência do arranjo espacial de plantio e da época da gema apical em algodoeiro herbáceo. Pesquisa Agropecuária Brasileira. v. 28, n. 12, p. 1379-1384. dez., 1993.

OOSTERHIUIS, D.M. Growth and development of a cotton plant. In: CIA, E.; FREIRE, E.C.; SANTOS, W.J. dos (Ed.). Cultura do algodeiro. Piracicaba: POTAFOS, 1999. p. 35-55.

ORNELlAS, A.P.; HIROMOTO, D.M.; YUYAMA, M.M.; CAMARGO, T.V. (Ed.) Boletim de Pesquisa de Algodão. Rondonópolis: Fundação MT, 2001. p.147-160. (Fundação MT. Boletim, 04)

PASSO, S.M.G. Algodão. Campinas: Instituto Campineiro de Ensino Agrícola, 1977. 424p. 
PENNA, J.C.V.; MESQUITA, D; FREIRE, E.C.; BELOT. J.L.; LANDIR, J.; LANZA, M.A.; FUZZATO, M.AGUIAR, P.A.; CANCI, P.C. Mesa redonda: sugestão de cultivares. In: CONGRESSO BRASILEIRO DE ALGODÃO, 3., Campo Grande, 2001. Livro de palestras. Campina Grande: EMBRAPA Algodão; Campo Grande: UFMS; Dourados: EMBRAPA Agropecuária Oeste, 2001. p.140-145.

REDDY, V.R.; BAKER, D.N., HODGES, H.F. Temperature and mepiquat chloride effects on cotton canopy architecture. Agronomy Journal, v. 82, n. 2, p. 190-195. 1990.

RIGHI, N.R.; FERRAZ, C.A.M.; CORRÊA, D.M. VII Cultura. In: INSTITUTO BRASILEIRO DE POTASSA. Cultura e adubação do algodoeiro. São Paulo, 1965. p.255-317.

ROSOLEM, C.A. Ecofisiologia e manejo da cultura do algodoeiro. Rondonópolis: Fundação MT, 2001. p.147-160. (Fundação MT. Boletim, 4)

SANTOS, E.A.; BORROSO, A.L.L.; PRADO, P.C.N. do. Efeito de fitoreguladores de crescimento em duas variedades de algodoeiro de porte e ciclos diferentes. In: REUNIÃO NACIONAL DO ALGODÃO, 5. Campina Grande, 1998. Resumos. Campina Grande: EMBRAPA,CNPA, 1988.150p.

SANTOS, W.J. dos. Planejamento e manejo integrado de pragas do algodoeiro. In: ENCONTRO SOBRE A CULTURA DO ALGODOEIRO, 1. Anais. Jaboticabal: FUNEP, 1998. p. 27-64.

SILVA, N.M.; RAIJ. B.van. Fibrosas. In: IAC. Boletim Técnico, 100. Campinas: IAC, 1996. p. 107-111. 
SOARES, J.J. Fitoreguladores e remoção da gema apical no desenvolvimento do algodoeiro. Scientia Agrícola. v. 56, n. 3, p. 627-630. jul./set., 1999.

SOUZA, L.C. Componentes de produção do cultivar de algodoeiro CNPA - 7H em diferentes populações de plantas. Viçosa, 1996. 71p. Dissertação (M.S.) Universidade Federal de Viçosa.

STUART, B.L.; ISBELL, V.R.; WENDT, C.W.; ABERNATHY, J.R. Modification of cotton water relations and growth with mepiquat chloride. Agronomy Journal, v. 76, p. 651-655. jul./aug., 1984.

THOMPSON, W.R. Cotton production for high yields and quality. In: CIA, E.; FREIRE, E.C.; SANTOS, W.J. Cultura do algodoeiro. Piracicaba: Potafos, 1999. p. 9-14.

WEAVER, R.J. Reguladores del crecimiento de las plantas en la agricultura. México: Trillas, 1976. 622 p.

WILLIFORD, J.R.; RAYBURN, S.T.; MERIDITH Jr., W.R.; Evaluation of a 76$\mathrm{cm}$ row for cotton production. Transactions of the ASAE, v. 29, p. 1544$1548,1986$.

YAMAOKA, R.S.; PIRES, J.R.; ALMEIDA, W.P. de. Efeito da densidade de plantas de algodoeiro sobre a inserção de ramos frutíferos. In: REUNIÃO NACIONAL DO ALGODÃO, 2. Salvador, 1982. Resumo dos trabalhos. Campina Grande: EMBRAPA, CNPA, 1982. p. 109.

YORK, A.C. Cotton cultivar response to mepiquat chloride. Agronomy Journal, v. 75, p. 663-667, jul./aug., 1983. 
ZHAO, D.; OOSTERHUIS, D. Evalbation or plant growth regulators for effect or the growth and yield of cotton. In: PROCEEDINGS BELTWIDE COTTON CONFERENCE. San Diego, 1998. Proceedings. Memphis: National Cotton Council of America, 1998. p. 1482-1484. 